\title{
O PROCESSO DE ANODIZAÇÃO DO ALUMÍNIO E SUAS LIGAS: UMA ABORDAGEM HISTÓRICA E ELETROQUÍMICA
}

\author{
João Victor de Sousa Araujo ${ }^{\mathrm{a}}$, Rejane Maria Pereira da Silva ${ }^{\mathrm{a}}$, Rafael Emil Klumpp ${ }^{\mathrm{a}}$ Issolda Costa ${ }^{\mathrm{a}, *,(\odot) ~}$ \\ ${ }^{a}$ Centro de Ciência e Tecnologia de Materiais, Instituto de Pesquisas Energéticas e Nucleares, Universidade de São Paulo, 05508-000 \\ São Paulo - SP, Brasil
}

Recebido em 20/10/2020; aceito em 12/03/2021; publicado na web em 08/04/2021

\begin{abstract}
THE ANODIZING PROCESS OF ALUMINUM AND ITS ALLOYS: A HISTORICAL AND ELECTROCHEMICAL APPROACH. $\mathrm{Al}$ and its alloys are found in several industrial applications. However, like most metals, this material is not immune to corrosion, being necessary to be protected against corrosion. One of the methods most commonly employed to improve the corrosion resistance of $\mathrm{Al}$ alloys is the anodizing process, which consists of thickening of the natural oxide $\left(\mathrm{Al}_{2} \mathrm{O}_{3}\right)$ presents in $\mathrm{Al}$ through anodic oxidation. The anodizing process is accomplished by immersion of the $\mathrm{Al}$ alloy into an acid bath and passing an electric current through it. This process produces two layers: a barrier layer thicker than the natural oxide and a layer with regular arrangement of nanopores (porous layer). This duplex structure forms the anodized layer with a large specific surface area. With the advent of nanotechnology, this layer has been applied in other areas due to its low cost, stability, absence of toxicity, and biocompatibility. In this context, this paper addresses a historical and electrochemical review of the anodizing process of $\mathrm{Al}$ and its alloys, presenting the main events that culminated in the development of the current processes and the understanding of the relationship between the chemical reactions and the mechanisms that occur during nucleation and development of the oxide layer.
\end{abstract}

Keywords: aluminum; electrochemistry; anodizing; nanotechnology.

\section{INTRODUÇÃo}

O alumínio ( $\mathrm{Al}$ ) é um dos elementos mais abundantes da crosta terrestre sendo encontrado na forma de óxido de alumínio $\left(\mathrm{Al}_{2} \mathrm{O}_{3}\right)$, denominado alumina. Ela é encontrada na Bauxita (que contem cerca de $60 \%$ de $\left.\mathrm{Al}_{2} \mathrm{O}_{3}\right),{ }^{1}$ o principal minério de $\mathrm{Al}$ descoberto em 1821 pelo geólogo Pierre Berthier na aldeia Les Baux-de-Provence, localizada no sul França. ${ }^{2}$ Foi isolado na forma metálica pela primeira vez em 1827 pelos cientistas Friedrich Wöhler e Hans Christian Orsted. ${ }^{3}$ Com o advento da revolução industrial, no início do século XIX, e a busca por materiais com boas propriedades químicas e físicas, foram desenvolvidos processos industriais para produção de $\mathrm{Al}$ metálico em larga escala, entre eles se destacam os processos Hall-Héroult, desenvolvido pelos engenheiros, Paul Héroult (francês) e Charles Martin Hall (americano) em 1886, ${ }^{4}$ e o processo Bayer, desenvolvido pelo químico austríaco Carl Joseph Bayer em 1889. ${ }^{4}$ Esses processos são usados para a produção de alumínio até hoje. ${ }^{5}$ Esses consistem na extração da $\mathrm{Al}_{2} \mathrm{O}_{3}$ da bauxita e, posteriormente, a obtenção do Al na forma metálica. ${ }^{1}$ Nesse mesmo período foi observado que adição de outros elementos ao $\mathrm{Al}$ puro, tais como: $\mathrm{Cu}, \mathrm{Mg}$, $\mathrm{Mn}$ e Fe, resultava em materiais com propriedades melhores que as dos aços convencionais, dessa forma foram desenvolvidas as ligas de $\mathrm{Al} .{ }^{6}$ Desde então, é possível encontrar o $\mathrm{Al}$ e suas ligas em diversas aplicações industriais, ${ }^{5,7}$ como na engenharia estrutural: estrutura de aviões, barcos, automóveis, bicicletas, tanques, carrocerias para ônibus e caminhões, indústria naval, vagões ferroviários , rebites, oleodutos, tubos de irrigação; na construção civil: janelas, portas, divisórias, grades, refletores, luminárias, painéis decorativos, coberturas, calhas, pisos antiderrapantes, placas de sinalização, persianas; nos utensílios domésticos: papel-alumínio, latas, embalagens Tetra Pak ${ }^{\circledR}$, etiquetas metálicas, tampas, pratos e bandejas descartáveis; e na indústria química e alimentícia, respectivamente nos trocadores de calor e latas para bebidas. ${ }^{5}$

*e-mail: icosta@ipen.br
Contudo, assim como a maioria dos metais, o Al e suas ligas não estão imunes a corrosão. ${ }^{8-10}$ Dessa forma, faz-se necessário métodos de prevenção contra corrosão, ${ }^{8}$ tais como: proteção catódica, proteção anódica, uso de inibidores de corrosão, eletrodeposição, uso de revestimentos metálicos, revestimentos orgânicos, revestimentos cerâmicos e revestimentos não metálicos, nesse último se destaca o processo de anodização, ${ }^{11}$ que nos últimos anos tem sido amplamente usado para proteção contra corrosão do $\mathrm{Al}$ e suas ligas.

Para os metais passiváveis, como o Al, as propriedades de resistência à corrosão devem-se primordialmente à formação natural de uma película de óxido, com alguns nanômetros de espessura que isola o metal do meio. ${ }^{9,12,13} \mathrm{O}$ processo de anodização consiste no espessamento desse óxido por meio da aplicação de um potencial ou corrente anódica ao metal. ${ }^{14}$ Para o Al, esse procedimento gera a formação de duas camadas, uma camada de óxido mais espessa que o óxido natural e com resistência à corrosão superior à essa, denominada camada barreira, e outra camada mais espessa que a barreira, que apresenta uma estrutura de poros ordenados, denominada camada porosa. Essas duas camadas juntas compõem a camada anodizada (CA) ${ }^{11,14,15}$ A Figura 1 ilustra a estrutura típica da CA do Al e suas ligas e suas principais características.

Nos últimos anos, com o advento da nanotecnologia, o uso da CA não se restringiu apenas para prevenção da corrosão, mas também para outras aplicações, como: ${ }^{15,16}$ máscaras para formação de materiais nanoestruturados, filtros para separação molecular, recipientes para catálise química, em aplicações biomédicas para entrega local de drogas, nano locais para implantes biomédicos e crescimento celular, na fabricação de células solares e combustíveis. A Figura 2 exemplifica os diferentes setores onde atualmente se utilizam processos de anodização.

Vale destacar que hoje em dia a formação da CA descrita na Figura 1, também é relatada para outros metais, como Ti, Ta, Hf, $\mathrm{W}, \mathrm{Zr}, \mathrm{Nb}$ e suas ligas. ${ }^{16}$ Contudo o $\mathrm{Al}$ e suas ligas ainda estão entre os materiais mais anodizados em termos industriais. ${ }^{11}$ Dessa forma, este artigo tem por objetivo servir como fonte de estudo para esse 


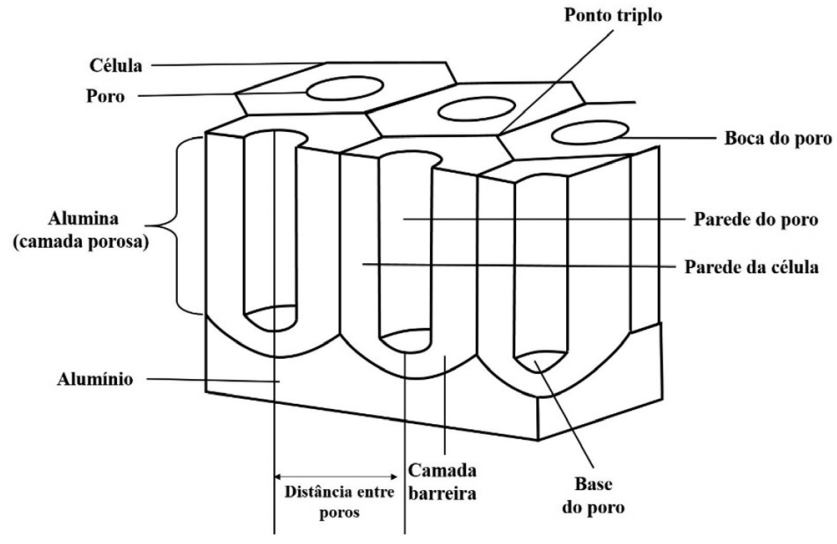

Figura 1. Ilustração esquemática da estrutura da camada anodizada. Baseado na ref. 15

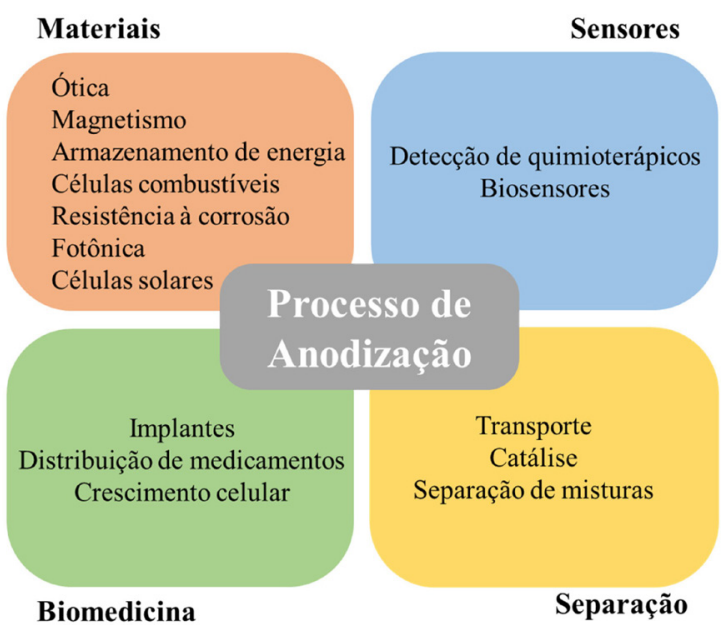

Figura 2. Esquema das principais aplicações da anodização. Baseado na ref. 16

vasto assunto, fornecendo uma concepção histórica e eletroquímica dos processos envolvidos na formação da CA do Al, além de abordar as condições experimentais apropriadas, servindo como um "review" para técnicos, químicos e engenheiros que atuam na área da nanotecnologia, proteção contra corrosão, ou que tenham interesse nesse assunto.

\section{UMA BREVE HISTÓRIA DA ANODIZAÇÃO DO ALUMÍNIO}

Há mais de 100 anos que o processo de anodização do $\mathrm{Al}$ tem sido estudado. Em 1855, o cientista britânico Sir Charles Wheatstone iniciou uma pesquisa para caracterizar o $\mathrm{Al}$ de forma que pudesse ser incorporado em uma série galvânica. ${ }^{17} \mathrm{Com}$ base em suas observações, concluiu que o Al não poderia ter um lugar fixo na série eletromotriz, isso porque a condição do Al variava, dependendo da composição do eletrólito utilizado. Dois anos mais tarde, em 1857, o cientista alemão Buff ${ }^{18}$ reportou algumas das observações feitas por Wheatstone. Em seu trabalho ele verificou que o $\mathrm{Al}$ quando polarizado anodicamente em solução ácida formava uma camada de óxido mais espessa que a natural. Dessa forma, Buff afirmou que "um metal é passivo quando, sob o efeito de uma solução na qual está imerso, torna-se revestido com um óxido insolúvel; ou, adicionalmente, quando polarizado em um eletrólito ácido, mesmo que não haja nenhuma camada de óxido visível, o metal resiste a novos ataques" ${ }^{11,18}$ Essa observação deu início a uma onda de pesquisas e trabalhos experimentais em muitos países. O primeiro cientista a reportar a passivação do $\mathrm{Al}$ através de reações químicas foi o francês Eugene Ducretet em $1875 .{ }^{19}$ Baseado no trabalho de Buff, ele observou que o Al quando polarizado em meio aquoso mudava de cor, isso foi atribuído ao óxido anódico $\left(\mathrm{Al}_{2} \mathrm{O}_{3}\right)$ formado por dissolução eletroquímica. Dessa forma, Eugene descreveu que a interação do Al com oxigênio formava alumina. A fim de completar os estudos de Ducretet, o cientista alemão Charles Pollak, em 1896, desenvolveu a primeira célula eletroquímica de anodização. ${ }^{20}$ Além disso, Charles deu início à investigação das propriedades do óxido anódico no Al, e descobriu que esse poderia ter aplicações industriais, principalmente aumentando a resistência à corrosão do $\mathrm{Al}$ e suas ligas. Essa teoria deu início à pesquisa industrial, que prosseguiu entre os anos de 1900 até 1920 com o objetivo de encontrar aplicações comerciais para o óxido anódico formado pela dissolução eletroquímica do Al. ${ }^{11}$ Durante a primeira guerra mundial, entre 1914 a 1918, os britânicos observaram que a estrutura de seus navios e aviões estavam se degradando muito rápido devido à corrosão marítima. Nesse mesmo período, foi verificado que o Al quando polarizado em meio ácido produzia um óxido mais resistente a corrosão que o formado naturalmente. Assim, em 1923, Bengough e Sutart, ${ }^{21}$ cientistas britânicos, desenvolveram a primeira patente de anodização do $\mathrm{Al}$ com ácido crômico $\left(\mathrm{H}_{2} \mathrm{CrO}_{4}\right)$; contudo, ela só foi aplicada em materiais para fins bélicos. Pouco tempo depois, em 1925, os americanos também patentearam um modo de proteção contra corrosão, patente requisitada pela ALCOA ${ }^{\circledR}$ (empresa americana líder mundial na produção de $\mathrm{Al}$ e suas ligas). A patente da $\mathrm{ALCOA}^{\circledR}$ foi a primeira patente comercial de anodização com diferentes eletrólitos, ${ }^{22,23}$ como sulfeto de amônio $\left(\left(\mathrm{NH}_{4}\right)_{2} \mathrm{~S}\right)$ e polissulfeto de amônio $\left(\left(\mathrm{NH}_{4}\right)_{2} \mathrm{~S}_{3}\right)$. Após dois anos, o cientista britânico Gower desenvolveu a primeira patente comercial ${ }^{24} \mathrm{com}$ ácido sulfúrico $\left(\mathrm{H}_{2} \mathrm{SO}_{4}\right)$, e desde então muitas outras patentes foram desenvolvidas com diferentes eletrólitos. ${ }^{11}$

Na década de 1930, importantes fatos aconteceram no campo da anodização do Al. Após inúmeras patentes e bons resultados nas aplicações industriais, o processo de anodização começa a ser tratado como um tratamento de superfície, ${ }^{25}$ ou seja, começou a ser utilizado nas linhas industriais como um processo de proteção contra corrosão das ligas de $\mathrm{Al}$ usadas em diversas estruturas. A partir de 1932 surgiram publicações de trabalhos em revistas científicas sobre a natureza do filme anódico e suas propriedades, como: mecanismos de formação da $\mathrm{CA} ;{ }^{26}$ determinação da natureza química e cristalográfica do óxido formado pelo processo de anodização; ${ }^{27}$ esquematização das possíveis reações químicas que ocorrem durante a formação da CA e a classificação das camadas formadas: ${ }^{28-30}$ discussão sobre a formação de um campo elétrico durante o processo, ${ }^{31}$ a formação da CA através de modelos matemáticos. ${ }^{32}$

No início da década 1940, os funcionários da $\mathrm{ALCOA}^{\circledR}$, Junius Edwards e Fred Keller ${ }^{33}$ publicaram no "Journal Of The Electrochemical Society”, uma importante revista cientifica, imagens metalográficas identificando quais os tipos de camadas são formadas durante o processo de anodização, confirmando assim as teorias e resultados propostos nos trabalhos publicados na década anterior. Além disso, verificaram que havia uma relação entre voltagem e o crescimento do óxido. Esse resultado foi importante para otimização do processo industrial. Entre 1947 e 1949, Mott et $a l .{ }^{34,35}$ publicaram dois artigos sobre a teoria de formação dos filmes de óxido de proteção em metais. Devido ao crescimento do processo de anodização na indústria, no final dos anos 40, o pesquisador britânico Simon Wernick ${ }^{36}$ publicou um artigo na revista cientifica "Nature" sobre os diferentes processos químicos de revestimentos usados no $\mathrm{Al}$ e suas ligas. No trabalho de Wernick, ${ }^{36}$ pela primeira vez o processo industrial de oxidação eletroquímica do $\mathrm{Al}$ é chamado de "anodização". Desde então, esse termo tem sido utilizado na indústria e no meio acadêmico. 
Com o desenvolvimento tecnológico, o uso do microscópio eletrônico de varredura (MEV) proporcionou uma melhor compreensão da estrutura da CA. Keller et al. ${ }^{37}$ publicaram em 1953 um dos mais famosos artigos sobre a estrutura da CA. Nesse trabalho, foi realizada pela primeira vez a caracterização da camada CA por $\mathrm{MEV}$, onde foi possível visualizar a camada barreira e a camada porosa, confirmando assim os trabalhos publicados anteriormente. Além disso, os autores discutiram a influência da variação de potencial aplicado nas características químicas e geométricas da CA, fornecendo uma melhor compreensão para a comunidade industrial e científica. Em 1954, o pesquisador britânico Simon Wernick em colaboração com outros pesquisadores ${ }^{38}$ publicaram um dos mais famosos livros sobre tratamento de superfície "The Surface Treatment and Finishing of Aluminum and Its Alloys". No livro, os autores dedicaram alguns capítulos ao processo de anodização e sua importância industrial e científica. No trabalho afirmaram que a "anodização havia se tornado sinônimo do tratamento de superfície do alumínio para sua proteção”. No final da década de 50 começa a ser discutido as propriedades elétricas da $\mathrm{CA},{ }^{39}$ visando outras aplicações.

Entre 1961 e 1965, importantes estudos ${ }^{39-41}$ foram publicados sobre a influência da composição dos eletrólitos e da temperatura do banho nas características da CA. Os resultados permitiram observar que a camada anódica formada no $\mathrm{Al}$ pelo processo de anodização pode ser influenciada por vários fatores. Essa informação foi de grande relevância para a indústria. Além disso, nesses trabalhos foi abordada a migração do metal e do oxigênio durante a formação de filme anódico. Com o intuito de resumir todas as teorias, observações e modelos propostos para formação da CA, em 1969, Diggle et $a l .{ }^{42}$ publicaram o primeiro artigo de revisão sobre o processo de anodização, aumentando a visibilidade desse tema. Nesse mesmo ano, o pesquisador americano Arthur William Brace publicou o livro "The technology of anodizing aluminium", ${ }^{43}$ o qual fornece uma visão técnica do processo de anodização na indústria, seu desenvolvimento e otimização.

A curiosidade pela visualização da escala atômica culminou no desenvolvimento do Microscópio Eletrônico de Transmissão (MET) no início dos anos $70 .{ }^{44}$ Esse foi um grande passo para o estudo da $\mathrm{CA}$, dando início à comprovação das teorias propostas nas décadas anteriores, a partir de imagens obtidas por MET em alta resolução. No decorrer da década de 70 e em diante se destacaram os trabalhos de O'Sullivan et al., ${ }^{45,46}$ Thompson et al.,${ }^{47-49}$ Skeldon et al. ${ }^{50}$ e Dell'oca et al. ${ }^{51}$ publicados em revistas de alta visibilidade. Esses pesquisadores caracterizaram a CA usando a técnica de MET e citaram os possíveis erros de interpretação dos dados eletroquímicos obtidos em laboratório.

No início dos anos 1980, o consultor industrial e cientista inglês V. F. Henley escreveu, a convite da editora inglesa PERGAMON $\mathrm{OXFORD}^{\circledR}$, o primeiro livro sobre a oxidação anódica do $\mathrm{Al}$ e suas ligas, ${ }^{52}$ fornecendo assim aos meios acadêmico e industrial uma explicação mais detalhada sobre a anodização do Al.

No início da década de 90, o uso europeu de Al para o setor de construção foi de cerca de um milhão de toneladas, sendo que $45 \%$ do total foi anodizado. ${ }^{11}$ Esse fato deu início à preocupação com anodização crômica $\left(\mathrm{H}_{2} \mathrm{CrO}_{4}\right)$ devido à toxicidade do cromo hexavalente $(\mathrm{Cr}(\mathrm{VI}))$ proveniente dos banhos de anodização. ${ }^{53,54}$ Dessa forma, estudos visaram a substituição do $\mathrm{H}_{2} \mathrm{CrO}_{4}$ por outros eletrólitos em escala industrial. ${ }^{55}$ Também nessa mesma década, em 1992, Parkhutik ${ }^{56}$ propôs um modelo matemático para formação das camadas barreira e porosa. O estudo foi de grande importância para os químicos e engenheiros que puderam usar a anodização do Al em outros setores e materiais, com diversas aplicações nanotecnológicas. No início dos anos 2000, a indústria aeroespacial classificou a anodização como o principal tratamento de superfície contra a corrosão das ligas de Al utilizadas na estrutura de aeronaves comerciais como: Boeing e Airbus. ${ }^{57}$ Nesse mesmo período, a anodização crômica deu espaço à sulfúrica-tartárica que mostrou bons resultados obtidos por meio de pesquisas científicas. ${ }^{58-61} \mathrm{Em}$ 2014, os cientistas coreanos Woo Lee e Sang-Joon Park publicaram o artigo de revisão "Porous Anodic Aluminum Oxide: Anodization and Templated Synthesis of Functional Nanostructures" 62 em uma importante revista científica a "Chemical Reviews" pertencente $\grave{a}$ organização norte-americana de químicos "American Chemical Society”. Nesse trabalho, os autores abordaram os diferentes conceitos químicos e físicos presentes durante a formação da CA e principalmente sua aplicação dentro do campo nanotecnológico, fornecendo um panorama das diferentes estruturas que podem ser obtidas e como podem ser usadas, servindo como artigo para diversas áreas científicas. Vale destacar que esse trabalho já foi citado por mais de 679 publicações, ${ }^{63}$ o que faz dele uma referência para conhecimento do uso do processo de anodização na área nanotecnológica. Recentemente, em 2018, a pesquisadora e consultora da empresa CompCote $^{\circledR}$, localizada nos EUA e especializada em tratamento de superfície do Al e suas ligas, Jude Mary Runge, publicou o livro "The Metallurgy of Anodizing Aluminum". ${ }^{11}$ Nesse livro, os conceitos sobre o processo de anodização do Al são revisados, dando assim, uma nova compreensão dos mecanismos que ocorrem $\grave{a}$ medida que a CA é formada. Acredita-se que o processo de anodização ainda tem muito a oferecer no campo industrial e muito há ainda a ser descoberto no campo científico.

A Figura 3 resume os principais acontecimentos listados sobre o processo de anodização do Al e suas ligas nas últimas décadas.

\section{O ESTUDO DO PROCESSO DE ANODIZAÇÃO DO AI NA COMUNIDADE CIENTÍFICA}

O processo de anodização do Al e suas ligas tem sido cada vez mais explorado pela comunidade científica. ${ }^{11}$ Nos últimos anos muitas patentes têm sido registradas com objetivo de otimizar o processo de anodização. ${ }^{64-70} \mathrm{~A}$ CA obtida por meio desse processo tornou-se sinônimo de proteção contra corrosão, durabilidade e decoração desses materiais. ${ }^{71} \mathrm{O}$ uso desse processo aumentou significativamente nos últimos anos; por exemplo, o mercado da anodização arquitetônica na Europa foi estimado em 200 milhões de $\mathrm{m}^{2}$ por ano. ${ }^{72}$ Dessa forma, diversos estudos têm sido desenvolvidos nas universidades em parceria com as indústrias visando: a otimização do processo, compreensão dos fenômenos químicos e físicos, influência dos parâmetros de anodização no desenvolvimento da CA. A Figura 4 mostra o número de publicações relacionadas com o processo de anodização do $\mathrm{Al}$ em função do tempo.

Observa-se que a partir da década de 90 o número de publicações cresceu significativamente. Esse fato ocorreu principalmente devido ao advento da nanotecnologia que possibilitou a utilização da CA em novos campos de aplicação, tais quais: arquitetura, indústria automotiva, indústria aeroespacial, dispositivos biomédicos e eletrônicos. Dessa forma, hoje é possível encontrar diversos trabalhos sobre o processo de anodização e seu uso em diversas áreas científicas, como: ciência dos materiais, engenharia metalúrgica, física aplicada, eletroquímica, tratamento de superfície e nanociência/ nanotecnologia. . $^{73,74}$

Resultados obtidos nessas áreas de pesquisa também estão disponíveis em várias monografias. ${ }^{55,75-83}$ Contudo, alguns países e universidades se destacam no estudo e uso do processo de anodização do Al, tornando-se referência nesse assunto. A Figura 5 mostra a porcentagem contribuição das universidades, países, autores e revistas científicas nas publicações sobre anodização do $\mathrm{Al}$ e suas ligas. 


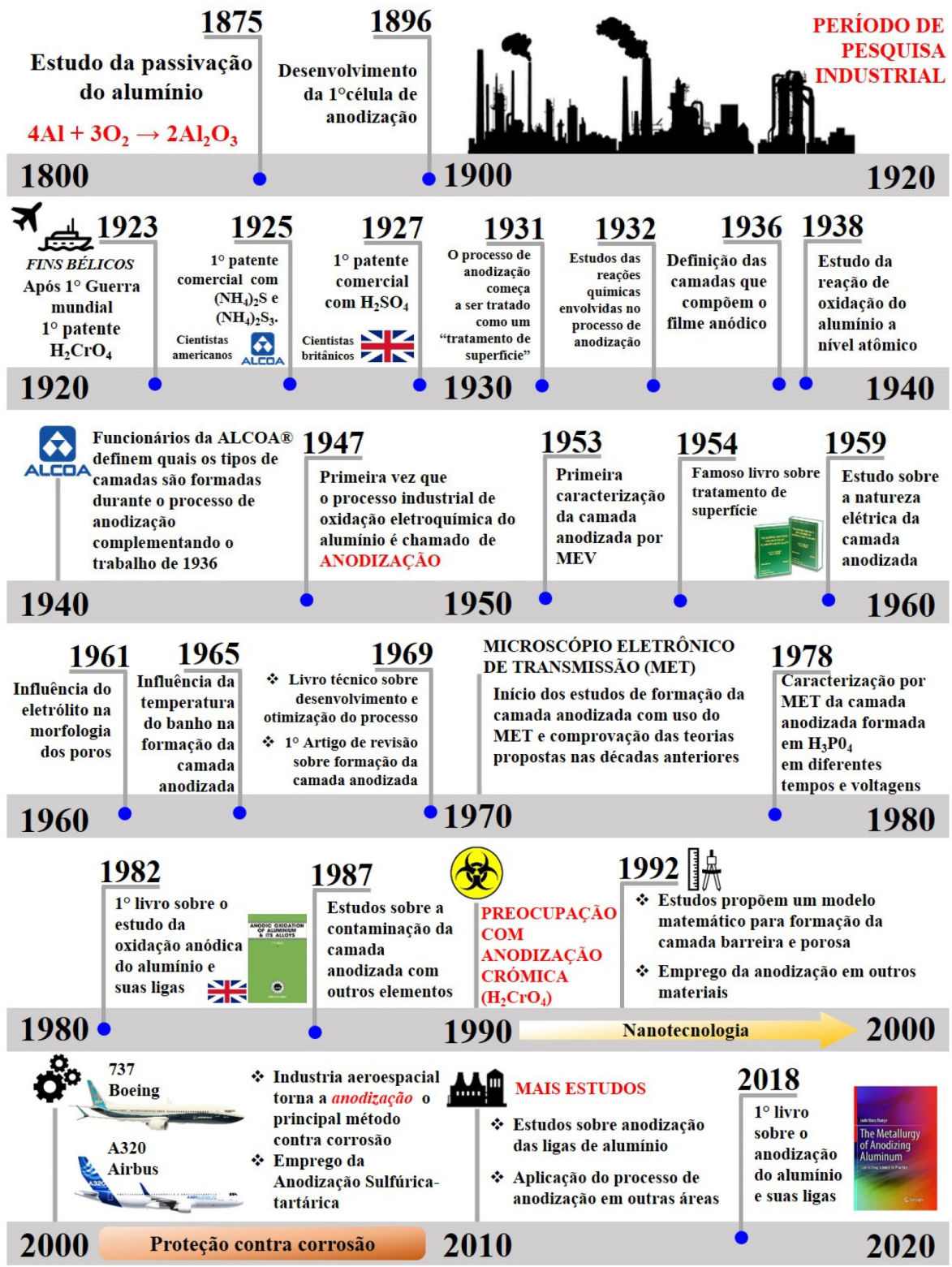

Figura 3. Linha cronológica dos principais acontecimentos do processo de anodização do Al e suas ligas

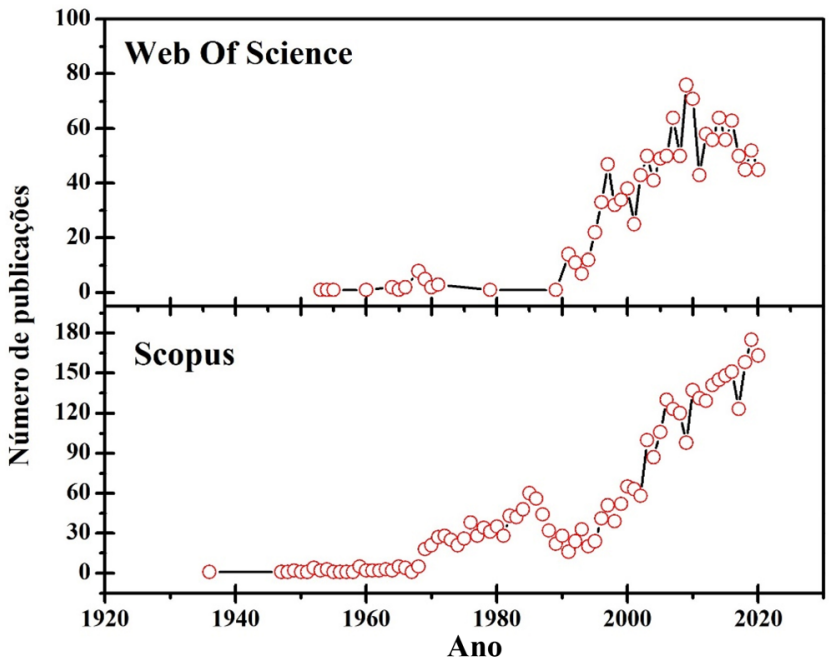

Figura 4. Número de publicações sobre anodização das ligas de Al em função do tempo. Dados obtidos através das plataformas Web of Science ${ }^{73}$ e Scopus ${ }^{74}$ utilizando no campo de busca a palavra-chave "Al anodizing"
A Universidade de Manchester ("University of Manchester") localizada na Inglaterra, se destaca no estudo da anodização do $\mathrm{Al}$, contribuindo com o maior número de trabalhos científicos desenvolvidos. ${ }^{14,47-50,58,85-137}$ Por outro lado, devido ao crescimento econômico desenfreado, a China tem mostrado maior uso do processo de anodização nos últimos anos em suas linhas de produção, principalmente devido ao uso na construção civil e sua entrada no mercado internacional aeroespacial e naval. ${ }^{138-140}$ Porém, os trabalhos mais citados continuam sendo de autores professores e pesquisadores da Universidade de Manchester. Esses trabalhos encontram-se publicados em revistas com grande visibilidade no meio acadêmico, como: "Corrosion Science", "Electrochemical Acta" e $o$ "Jounal of the Electrochemical Society”, mostrando assim, a qualidade dessas produções e suas relevâncias para o meio científico e industrial. No Brasil, se destacam os trabalhos científicos liderados pelos pesquisadores descritos na Tabela 1 .

\section{O PROCESSO DE ANODIZAÇÃO NA INDÚSTRIA}

De acordo com a Associação Brasileira de Tratamento de 


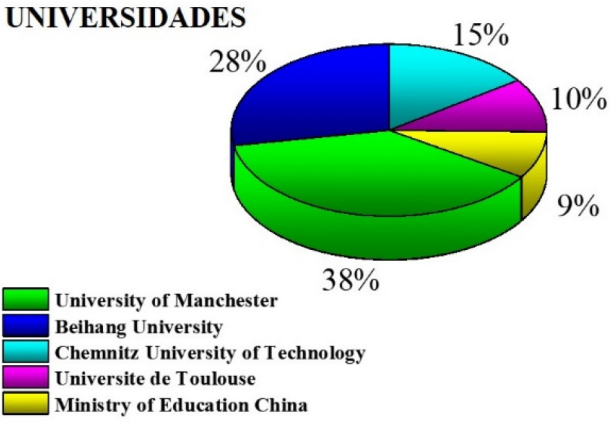

AUTORES

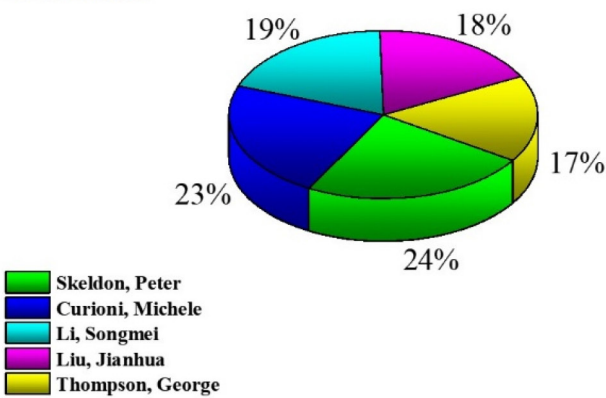

PAÍSES
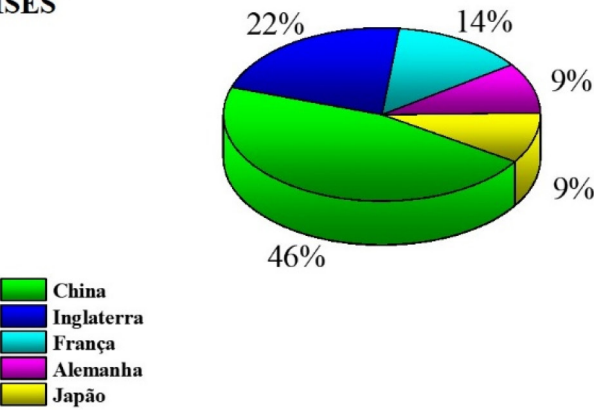

PERIÓDICOS

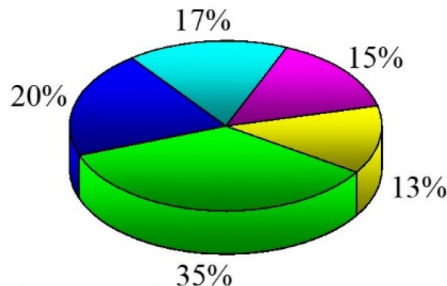

Coatings Technology and

Corrosion Science

Electrochimica Acta

Journal of the Electrochemical Society

Surface and Interface Analysis

Figura 5. Porcentagem de contribuição nas publicações sobre anodização do Al e suas ligas das (o) principais universidades, países, autores e revistas cientificas. Dados obtidos através da plataforma SciVa ${ }^{84}$ utilizando no campo de busca a palavra-chave "Al anodizing"

Tabela 1. Trabalhos científicos publicados sobre processo de anodização de $\mathrm{Al}$ e suas ligas realizados por grupos de pesquisadores no Brasil

\begin{tabular}{|c|c|}
\hline Pesquisador & Instituição \\
\hline $\begin{array}{l}\text { Costa } \text { et al. } .^{60,141-143} \\
\text { Pessine } \text { et al. }{ }^{144}\end{array}$ & $\begin{array}{l}\text { Instituto de Pesquisas Energéticas e Nucleares } \\
\text { (IPEN/CNEN-SP) }\end{array}$ \\
\hline Mello et al. ${ }^{59,61,81,82,145-147}$ & $\begin{array}{c}\text { Departamento de Engenharia Metalúrgica e de } \\
\text { Materiais (PMT-USP) }\end{array}$ \\
\hline Salcedo et al..$^{77}$ & $\begin{array}{l}\text { Instituto de Física da Universidade de São Paulo } \\
\text { (IFUSP) }\end{array}$ \\
\hline $\begin{array}{l}\text { Dick et al. }{ }^{148-152} \\
\text { Teixeira } \text { et al. }{ }^{153,154} \\
\text { Ferreira } \text { et } \text { al. }{ }^{155}\end{array}$ & $\begin{array}{l}\text { Universidade Federal do Rio Grande do Sul } \\
\text { (UFRGS) }\end{array}$ \\
\hline $\begin{array}{l}\text { Voorwald et al. }{ }^{156} \\
\text { Guimarães } \text { et } \text { al. } .^{157}\end{array}$ & Universidade Estadual de Ponta Grossa (UEPG) \\
\hline Rodrigues et al. ${ }^{158,159}$ & Universidade Estadual Paulista (UNESP) \\
\hline
\end{tabular}

Superfície (ABTS), aproximadamente 40 indústrias utilizam o processo de anodização em suas linhas de produção no Brasil. ${ }^{160}$ Como já mencionado, durante o processo de anodização ocorre espessamento da camada de óxido natural do alumínio $\mathrm{Al}_{2} \mathrm{O}_{3}$, produzindo assim uma camada protetora altamente impermeável em sua superfície. As características da CA, como a espessura da camada barreira e diâmetro dos poros na camada porosa, são dependentes da voltagem aplicada durante o processo..$^{91,161,162}$ A Figura 6 apresenta graficamente os resultados da variação da tensão e da corrente na superfície de uma amostra de Al.

Verifica-se que em baixas tensões e altas correntes, ocorre corrosão do material, enquanto em tensões mais altas e correntes mais baixas ocorrem efeitos de polimento eletrolítico. À medida que o potencial aumenta, forma-se a CA e a corrente diminui. Subsequentemente, à medida que o potencial aumenta, uma camada porosa é formada e a corrente diminui. E, finalmente, à medida que a voltagem aumenta, a corrente diminui e uma camada porosa é formada. Dessa forma, a indústria utiliza parâmetros específicos com a finalidade de se obter uma camada com características definidas, trabalhando com altas

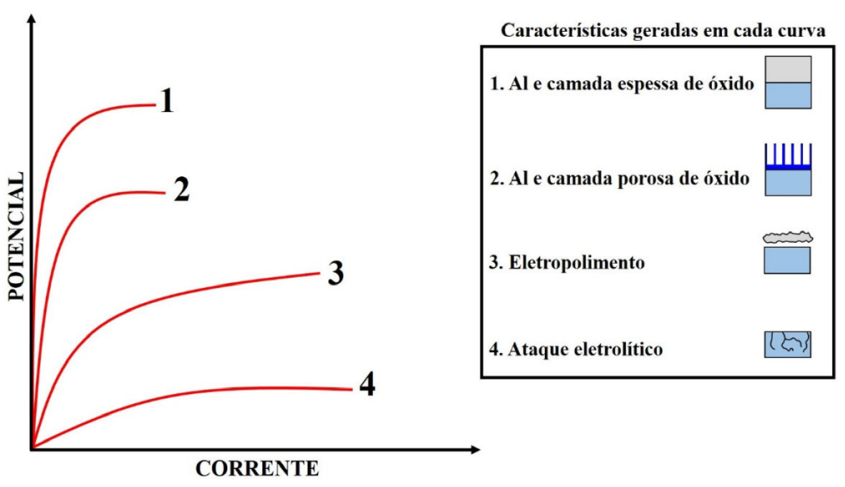

Figura 6. Ilustração esquemática da polarização anódica do alumínio, mostrando os resultados da variação da tensão e da corrente na superfície de uma amostra de Al. Baseado na ref. 163

voltagens e baixas correntes, sendo essas as principais variáveis do processo..$^{71}$ Mudando essas variáveis, a característica desejada pode ser obtida (seja na forma de tamanho de poro ou diâmetro de poro). $\mathrm{Na}$ anodização, o $\mathrm{Al}$ é conectado ao polo positivo de uma fonte de alimentação e imersa no eletrólito adequado. ${ }^{14}$ Outro metal, que seja eletricamente condutor e inerte no banho de anodização, é conectado ao polo negativo da fonte de alimentação. Um esquema ilustrativo de uma célula de anodização convencional é mostrado na Figura 7.

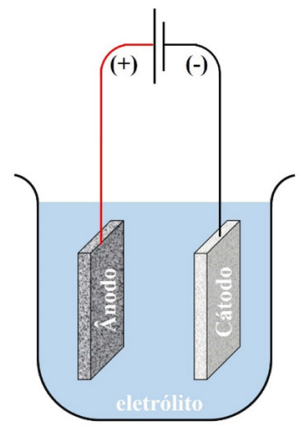

Figura 7. Ilustração esquemática de uma célula de anodização 


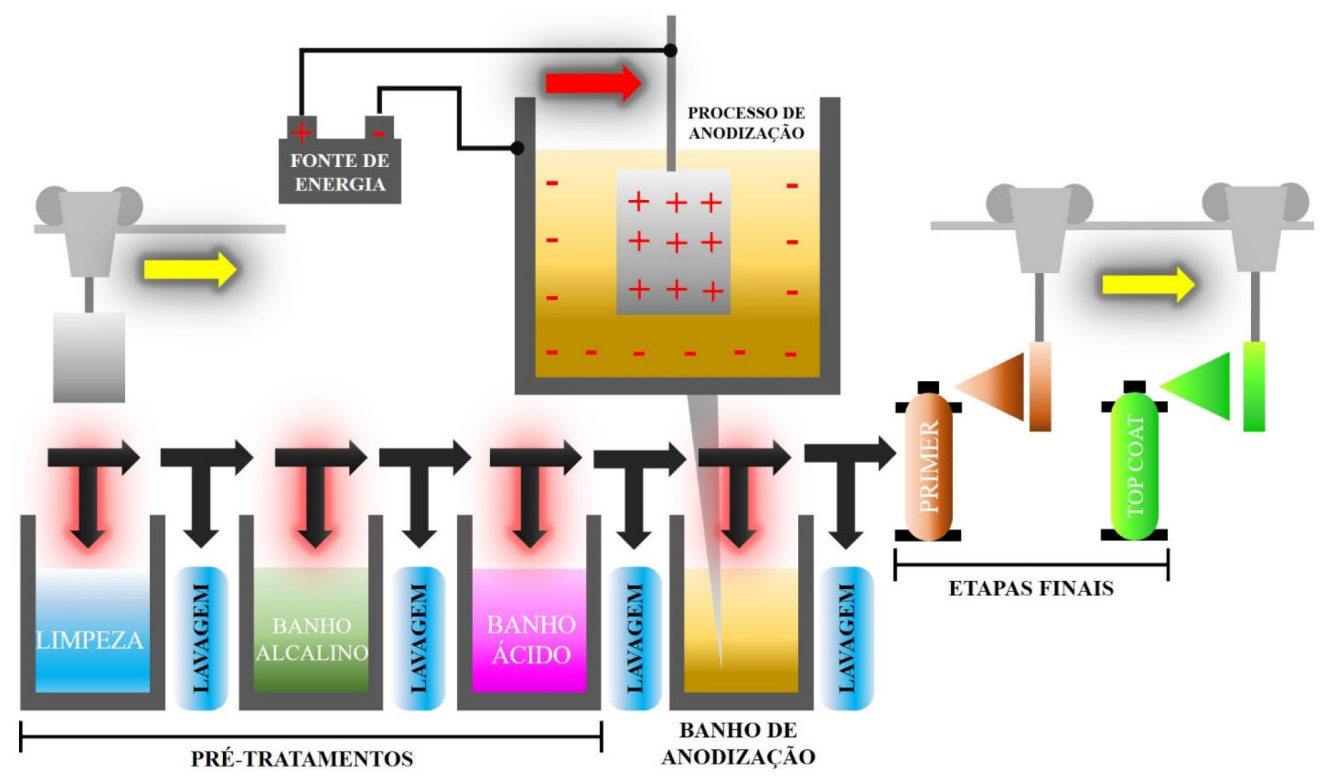

Figura 8. Ilustração esquemática do processo de anodização industrial

A linha de anodização industrial difere do esquema ilustrado na Figura 7 devido às etapas pré e pós processo de anodização do $\mathrm{Al}$, como mostra a Figura 8.

Vale destacar que o pré-tratamento é importante para retirada de oleosidades e impurezas presentes nas ligas, enquanto que as etapas finais completam o sistema de proteção das mesmas. ${ }^{102,164}$ A Figura 9 ilustra os componentes do sistema de proteção das ligas de Al que podem ser encontrados em estruturas automotivas, aeroespaciais e na construção civil.

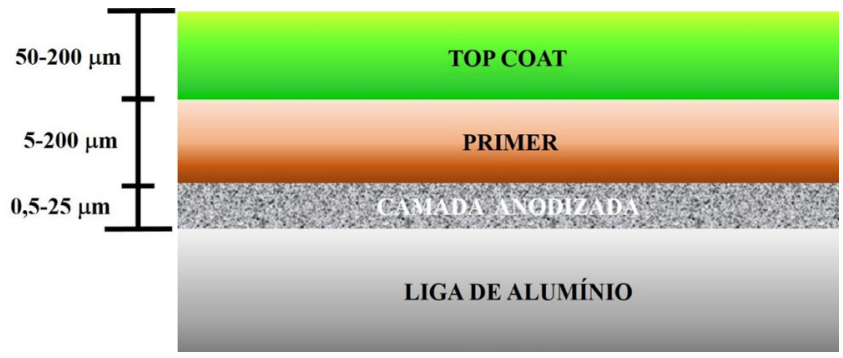

Figura 9. Ilustração esquemática dos componentes de um sistema de proteção das ligas de alumínio. Baseado na ref. 165

Tintas, primers e colas não aderem firmemente a um metal descoberto, mas a anodização fornece uma melhor adesão, além de aumentar a resistência à corrosão e resistência ao desgaste. ${ }^{161-163,165} \mathrm{~A}$ camada anódica é parte integrante do metal com uma estrutura porosa altamente ordenada que permite a impressão e selagem subsequente por tingimento. A estrutura microscópica do metal perto da superfície é alterada por anodização. ${ }^{165} \mathrm{~A}$ resistência máxima à corrosão é obtida pelo processo de selagem, uma vez que a camada de óxido formada durante a anodização é normalmente porosa por natureza, como esquematizado na Figura 1.

\section{PARAMÊTROS QUE INFLUENCIAM O PROCESSO DE ANODIZAÇÃO}

As características estruturais da CA são influenciadas por alguns parâmetros do processo de anodização. Os dois principais parâmetros que influenciam a morfologia da camada e em suas características químicas e físicas são a composição do eletrólito e a temperatura dele. ${ }^{166}$

\section{Composição do eletrólito}

Existem dois tipos de eletrólitos utilizados para anodização, os que favorecem apenas a formação da camada barreira e os que favorecem a formação da camada porosa, denominados eletrólitos do tipo barreira e poroso, respectivamente. O primeiro tipo tem como principal aplicação a fabricação de capacitores eletrônicos, embora também possam ser usados para fins de proteção. Contudo, por não promoverem a rugosidade presente na camada porosa, não fornecem a adesão necessária para o sistema mostrado na Figura $10 .{ }^{167}$ Sendo assim, a indústria opta pelos eletrólitos do tipo poroso. ${ }^{168}$

Os eletrólitos do tipo barreira mais comumente usados para aplicações de proteção são o tartarato de amônio $\left(\left(\mathrm{NH}_{4}\right)_{2} \mathrm{C}_{4} \mathrm{H}_{4} \mathrm{O}_{6}\right)$ e soluções de ácido bórico $\left(\mathrm{H}_{3} \mathrm{BO}_{3}\right){ }^{167}$ Entre os eletrólitos do tipo poroso se destaca o ácido sulfúrico, $\left(\mathrm{H}_{2} \mathrm{SO}_{4}\right)$, o mais amplamente usado em todo o mundo, substituindo assim o ácido crômico. ${ }^{11} \mathrm{Na}$ maioria das ligas de Al, esse eletrólito produz revestimentos anódicos incolores e transparentes que podem ser facilmente coloridos. ${ }^{166}$ Outros eletrólitos como os ácidos oxálico $\left(\mathrm{C}_{2} \mathrm{H}_{2} \mathrm{O}_{4}\right)$, fosfórico $\left(\mathrm{H}_{3} \mathrm{PO}_{4}\right)$, sulfônico $\left(\mathrm{H}-\mathrm{S}(=\mathrm{O})_{2}-\mathrm{OH}\right)$ e malônico $\left(\mathrm{C}_{3} \mathrm{H}_{4} \mathrm{O}_{4}\right)$ também são utilizados em algumas linhas de produção. ${ }^{11} \mathrm{O}$ processo que utiliza $\mathrm{C}_{2} \mathrm{H}_{2} \mathrm{O}_{4}$ produz revestimentos duros coloridos em ouro ou bronze claro, dependendo da liga utilizada. Contudo, esse processo é mais caro do que o que utiliza o $\mathrm{H}_{2} \mathrm{SO}_{4}$. Outra desvantagem é que ele produz rejeitos venenosos, assim como na anodização crômica $\left(\mathrm{H}_{2} \mathrm{CrO}_{4}\right){ }^{11}$ Os processos com os ácidos $\mathrm{H}_{3} \mathrm{PO}_{4}$ e $\mathrm{C}_{3} \mathrm{H}_{4} \mathrm{O}_{4}$ têm sido usados para anodização decorativa. ${ }^{169}$ Esses eletrólitos produzem filmes mais duros do que a anodização sulfúrica padrão, em cores que variam do bronze claro ao preto. ${ }^{169,170}$ Vale destacar que a espessura da CA diminui na respectiva ordem de acordo com o uso do eletrólito: ácido crômico > ácido fosfórico > ácido oxálico > ácido sulfúrico. Ácidos menos concentrados tendem a produzir revestimentos de óxidos que são mais duros, mais espessos, menos porosos e mais resistentes ao desgaste quando comparados com ácidos mais concentrados. ${ }^{171-176}$

\section{Temperatura do banho}

O aumento da temperatura do eletrólito é diretamente proporcional à dissolução do filme anódico, resultando assim em filmes mais finos, porosos e macios. Baixas temperaturas são usadas para produzir revestimentos duros normalmente em combinação com 
altas densidades de corrente e agitação vigorosa. ${ }^{80} \mathrm{Na}$ anodização decorativa e na protetora, normalmente são utilizadas temperaturas na faixa de $15-40{ }^{\circ} \mathrm{C} .{ }^{169}$ Se a temperatura for aumentada, a espessura máxima é reduzida para valores mais baixos devido ao maior poder de dissolução do óxido no eletrólito. ${ }^{177}$

\section{A ELETROQUíMICA DO PROCESSO DE ANODIZAÇÃo}

O desenvolvimento do filme poroso pode ser prontamente revelado pela mudança de tensão ou densidade de corrente durante a anodização. ${ }^{56,178} \mathrm{O}$ modelo aceito pela comunidade científica leva em consideração que a formação da CA ocorre por meio da dissolução assistida pelo campo elétrico (DAC) formado na superfície do metal o qual favorece a mobilidade dos íons e, consequentemente, a formação da CA. ${ }^{56,179}$ Nesse modelo existem quatro etapas básicas para o desenvolvimento do filme. Elas podem ser identificadas a partir das respostas de potencial-tempo ou densidade de corrente-tempo, conforme ilustrado esquematicamente na Figura 10, a qual também ilustra a morfologia do filme em cada estágio.

Durante o estágio I, forma-se a camada barreira que oferece pouca resistência à passagem de corrente. Posteriormente, os poros começam a se formar na superfície da camada barreira (estágio II) devido à chamada dissolução assistida pelo campo elétrico (DAC). Por causa da geometria da superfície externa da camada barreira, que é determinada por pré-tratamentos (mostrados na Figura 9), e pela microestrutura do material, o fluxo de corrente resulta no crescimento de alguns poros. Então, a morfologia clássica dos filmes porosos começa a surgir durante o estágio III. Consequentemente, o desenvolvimento em estado estacionário dos poros continua até o estágio IV. A iniciação e crescimento do filme anódico poroso podem ser diretamente examinados observando a seção transversal do $\mathrm{Al}$ anodizado por meio de ultramicrotomia. ${ }^{56,161,179}$ Vale destacar que as curvas densidade de corrente-tempo e potencial-tempo correspondem à sobreposição de dois processos, um deles representa a diminuição exponencial da formação da camada barreira, enquanto o segundo representa a corrente de formação da camada porosa. ${ }^{14} \mathrm{Um}$ rápido aumento da corrente é produzido e, posteriormente, ocorre uma queda lenta para um valor de estado estacionário. No caso da anodização da camada barreira, quando a tensão é mantida constante, a corrente inicial aumenta rapidamente, mas depois diminui para valores muito baixos, enquanto que o inverso ocorre com o potencial. No início da formação da camada barreira a corrente diminui e o potencial aumenta linearmente com tempo. Contudo, no início da formação da camada porosa o campo elétrico formado dá início à nucleação dos primeiros poros. Dessa forma, à medida que a camada porosa cresce, corrente e potencial aumentam até que o potencial de formação seja alcançado. Posteriormente, ambas variáveis, corrente e potencial, tornam-se constantes devido à resistência da camada formada.

De um modo geral, a mobilidade dos íons presentes no metal e no eletrólito favorecem a formação da CA. É amplamente aceito que para o crescimento da camada barreira e porosa, tanto os cátions $\mathrm{Al}^{3+}$ quanto os ânions $\mathrm{O}^{2-}$ ou $\mathrm{OH}^{-}$são móveis dentro do óxido anódico sob alto campo elétrico (E). ${ }^{42,51,91,132,133,180-182}$ Sendo assim, é proposta a seguinte sequência de reações químicas que ocorrem durante o desenvolvimento da CA: ${ }^{11,14,16,62,124,161,183,184}$

(I) $\mathrm{Na}$ interface metal/óxido

$$
\begin{gathered}
\mathrm{Al} \rightarrow \mathrm{Al}_{(\mathrm{ox})}^{3+}+3 \mathrm{e}^{-} \\
2 \mathrm{Al}_{(\text {ox })}^{3+}+3 \mathrm{O}_{(\mathrm{ox})}^{2-} \rightarrow \mathrm{Al}_{2} \mathrm{O}_{3}
\end{gathered}
$$

(II) $\mathrm{Na}$ interface óxido/eletrólito

$$
\begin{gathered}
2 \mathrm{H}_{2} \mathrm{O}_{(\mathrm{liq})} \rightarrow \mathrm{O}_{(\mathrm{ox})}^{2-}+\mathrm{OH}_{(\mathrm{ox})}^{-}+3 \mathrm{H}_{(\mathrm{aq})}^{+} \\
\mathrm{Al}_{2} \mathrm{O}_{3}+6 \mathrm{H}_{(\mathrm{aq})}^{+} \rightarrow 2 \mathrm{Al}_{(\mathrm{aq})}^{3+}+3 \mathrm{H}_{2} \mathrm{O}_{(\mathrm{liq})} \\
2 \mathrm{Al}_{(\mathrm{ox})}^{3+}+3 \mathrm{O}_{(\mathrm{ox})}^{2-} \rightarrow \mathrm{Al}_{2} \mathrm{O}_{3} \\
\mathrm{O}_{(\mathrm{ox})}^{2-} \rightarrow \mathrm{O}_{2(\mathrm{~g})}+2 \mathrm{e}^{-}
\end{gathered}
$$
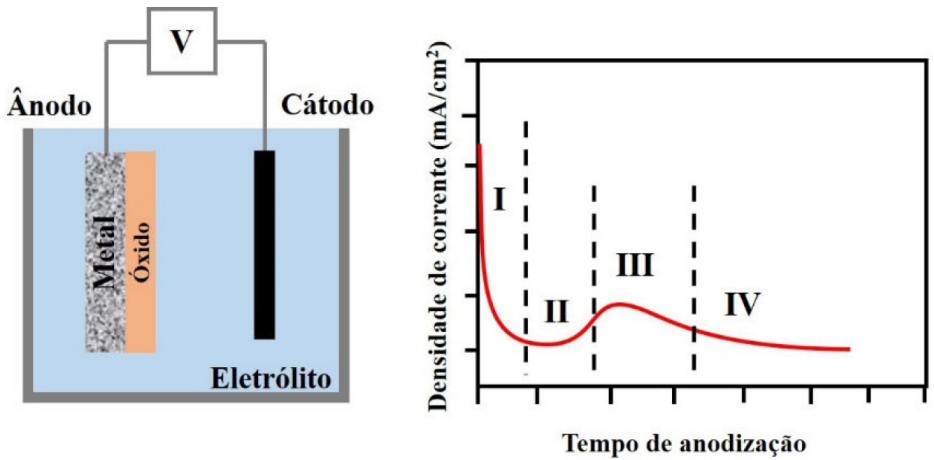

Tempo de anodização

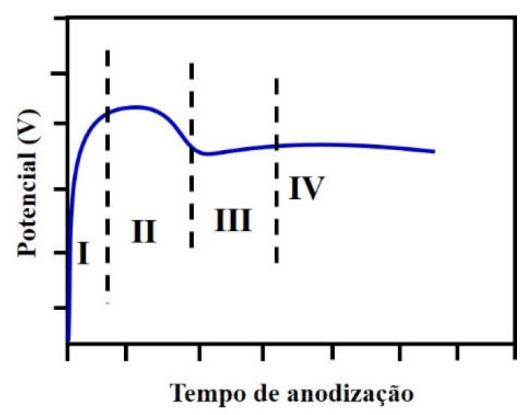

Tempo de anodização

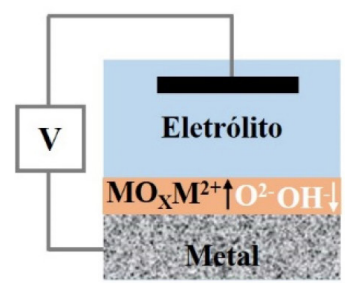

I

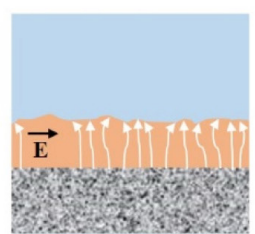

II

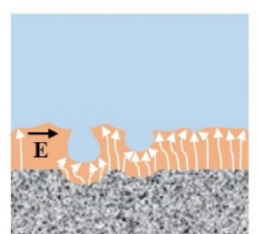

III

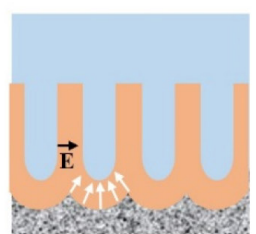

IV

Figura 10. Ilustração esquemática do processo de formação da camada anodizada, incluindo configuração de célula eletroquímica e curva de densidade de corrente-tempo e potencial-tempo típicas do processo anodização do alumínio e suas ligas. Estágios de crescimento dos poros: (I) formação da camada de óxido; (II) formação de poços por heterogeneidades locais de campo elétrico; (III) formação inicial de poros; (IV) crescimento dos poros em condiçães de estado estacionário. Baseado nas refs. 16 e 56 
(III) Na superfície do cátodo

$$
6 \mathrm{H}_{(\mathrm{aq})}^{+}+6 \mathrm{e}^{-} \rightarrow 3 \mathrm{H}_{2(\mathrm{~g})}
$$

(IV) Equação geral do processo

$$
2 \mathrm{Al}_{(\text {sol })}+3 \mathrm{H}_{2} \mathrm{O}_{(\text {liq })} \rightarrow \mathrm{Al}_{2} \mathrm{O}_{3(\mathrm{ox})}+3 \mathrm{H}_{2(\mathrm{~g})}
$$

\section{Formação da camada barreira}

Como já mencionado, a camada barreira possui menor aplicação industrial quando comparada com a porosa. O filme anódico do tipo barreira formado sobre o Al é uma camada de alumina amorfa de espessura uniforme ${ }^{87} \mathrm{O}$ crescimento do filme é conseguido através da migração de íons $\mathrm{Al}^{3+}$ e $\mathrm{O}^{2-}$ através do óxido no estado sólido, que se movem para fora e para dentro, respectivamente, através do filme. O transporte de espécies é impulsionado por um campo elétrico fornecido por uma fonte de alimentação externa. ${ }^{179} \mathrm{O}$ desenvolvimento do novo filme acontece devido à oxidação dos átomos de $\mathrm{Al}$ na interface metal/óxido, para formar novos íons $\mathrm{Al}^{3+}$, provenientes da reação (1), e adição de íons $\mathrm{O}^{2-} \mathrm{e} \mathrm{OH}^{-}$, derivados do eletrólito, na interface óxido/eletrólito. Como resultado da contra migração dos íons $\mathrm{Al}^{3+} \mathrm{e} \mathrm{O}^{2-}$, o novo filme é formado nas interfaces óxido/eletrólito e metal/óxido, como mostra a reação (2), numa proporção de $40 \%$ a $60 \% .{ }^{14}$ A Figura 11 ilustra o esquema da migração das espécies e as proporções do filme anódico formado por ingresso e saída dos íons $\mathrm{O}^{2-}$ e $\mathrm{Al}^{3+}$, respectivamente.

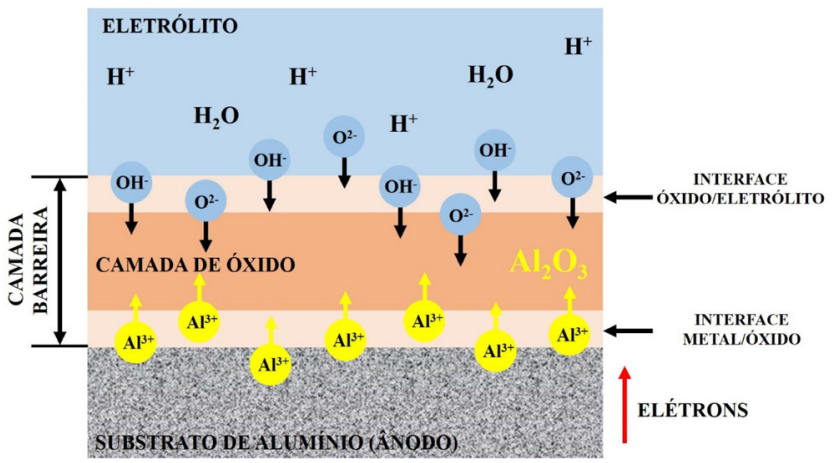

Figura 11. Ilustração esquemática do mecanismo de formação da camada de barreira. Baseado na ref. 161

As proporções do filme desenvolvidas em cada interface refletem as quantidades de corrente transportada por cátions e ânions. ${ }^{161}$ Tais proporções do filme são alcançadas na prática se o filme é formado em um eletrólito que não reage com o óxido. ${ }^{161} \mathrm{~A}$ espessura da camada barreira é limitada a um valor máximo de $20 \mathrm{~nm}$, devido à ruptura dielétrica, ${ }^{179}$ sendo proporcional à tensão de anodização com pequenas variações determinadas pelas condições do processo. De modo geral, a camada barreira previne o contato físico direto entre o eletrólito e a liga, aumentando assim a resistência à corrosão do $\mathrm{Al} .{ }^{97} \mathrm{No}$ final dessa etapa, a camada barreira está totalmente formada e permanece constante. Assim, o crescimento da camada diminui até um ponto em que a taxa de crescimento é igual à taxa de dissolução, mantendo a espessura praticamente constante. Além disso, a camada barreira resultante é dura, resistente ao desgaste e se comporta como um isolante elétrico. ${ }^{179,185}$

\section{Formação da camada porosa}

Para entender o mecanismo de formação da camada porosa é necessário compreender a formação da camada barreira. Diferente do mecanismo de crescimento da camada barreira, a formação da camada porosa ocorre na interface óxido/eletrólito devido à dissolução da camada barreira. ${ }^{16}$ Dessa forma, compreende-se que a camada porosa cresce à custa da camada barreira. A Figura 12 ilustra três estágios presentes durante a formação dessa camada.

No estágio 1, tem-se a formação da camada barreira. Estágio que se caracteriza pelo ingresso dos cátions $\mathrm{Al}^{3+}$ e dos aníons $\mathrm{O}^{2-}$ ou $\mathrm{OH}^{-}$ como exemplificado nas reações (1) e (2). Durante esse estágio, 70\% dos íons $\mathrm{O}^{2-}$ ou $\mathrm{OH}^{-}$contribuem para formação da camada barreira, enquanto $30 \%$ dos cátions $\mathrm{Al}^{3+}$ são dissolvidos no eletrólito. ${ }^{16}$ Os estudos ${ }^{186,187}$ obtidos através da técnica de ERS (Espectroscopia de Retrodispersão de Rutherford) mostraram que os cátions $\mathrm{Al}^{3+}$ que migram para fora, não contribuem para o crescimento do óxido na interface óxido/eletrólito, mas são todos liberados no eletrólito. Caso contrário, a saída de íons $\mathrm{Al}^{3+}$ formaria alumina anódica na interface óxido/eletrólito impedindo o desenvolvimento dos poros embrionários. ${ }^{161}$ Essa condição é um pré-requisito para formação da camada seguinte, etapa 2. Posteriormente é iniciada a formação dos poros. $\mathrm{O}$ campo elétrico formado devido à tensão aplicada favorece a mobilidade dos íons $\mathrm{Al}^{3+}, \mathrm{OH}^{-}$e $\mathrm{O}^{2-}$ provenientes da dissociação eletrolítica da água, reação (3), a qual supre os ânions de oxigênio para formação do óxido. Os cátions ejetados da camada barreira provenientes da reação (4) devido à dissolução da camada de óxido, contribuem para diminuição da eficiência da corrente e tensão (potencial), mostrados na Figura 11. Posteriormente, devido à mobilidade dos íons $\mathrm{Al}^{3+}, \mathrm{O}^{2-}$ e $\mathrm{OH}^{-}$na interface óxido/eletrólito temse a formação da camada porosa, reação (5), com suas características típicas como mostra o estágio 3. É importante salientar que, a formação da CA depende exclusivamente da mobilidade dos íons, ${ }^{179}$ como mostra a Figura 13.

O campo elétrico é proporcional à tensão elétrica aplicada. Dessa forma, quanto maior a tensão (potencial) mais rápido forma-se a CA
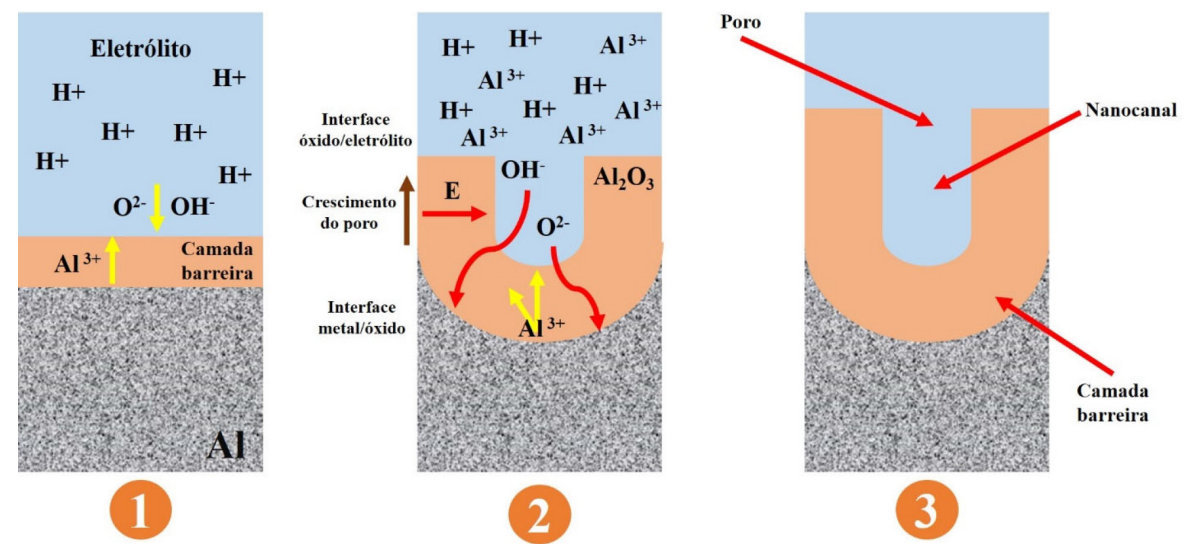

Figura 12. Ilustração esquemática do mecanismo de formação da camada porosa em um eletrólito ácido. Baseado na ref. 161 


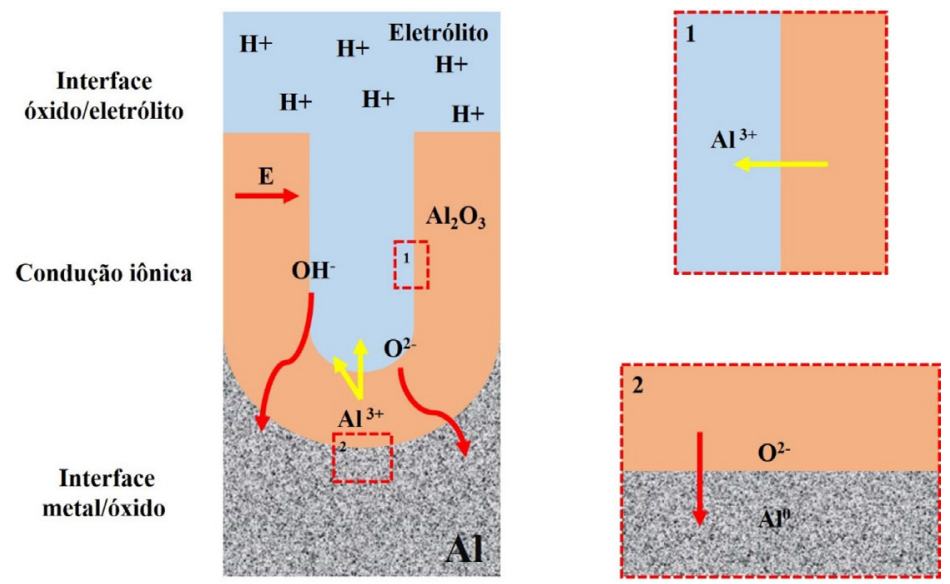

Figura 13. Ilustração esquemática do movimento dos íons durante a formação da camada porosa. Baseado na ref. 161

devido à maior mobilidade dos íons. ${ }^{179}$ Sendo assim, o que encerra o processo de formação da camada porosa é a diminuição da intensidade do campo elétrico nas paredes dos poros que tende a diminuir com o crescimento do mesmo, dando assim uma contribuição pequena para o fluxo de íons (condução iônica), o que também explica o fato de todo metal não ser consumido para formar a CA. Dessa forma, como observado na Figura 13, a diminuição do campo elétrico impede a condução iônica dos íons $\mathrm{OH}^{-}$e $\mathrm{O}^{2-}$ através do óxido dificultando as reações de oxidação metálica do $\mathrm{Al}$ na interface metal/óxido (reação 1) e ejeção dos cátions $\mathrm{Al}^{3+}$ na interface óxido/eletrólito (reação 4). Vale destacar que a ejeção dos cátions $\mathrm{Al}^{3+}$ presentes no óxido, conduz à formação de $\mathrm{H}_{2} \mathrm{O}$, que por sua vez, na presença do meio ácido, produz íons contendo oxigênio $\left(\mathrm{OH}^{-}\right.$e $\left.\mathrm{O}^{2-}\right)$, importantes para o desenvolvimento da camada porosa. Dessa forma, a não ejeção dos cátions $\mathrm{Al}^{3+}$ diminui a produção dos ânions $\mathrm{OH}^{-}$e $\mathrm{O}^{2-}$ e, como consequência, o processo é encerrado.

Alguns pesquisadores definem esse processo como auto catalítico ou ácido catalisado, ${ }^{62,171}$ contudo sem o fluxo dos ânions não é possível formar a camada. Dessa forma, é assumido que a DAC tem papel importante durante a formação da CA. Encerrado esse processo, tem-se a formação da camada porosa que cresce perpendicular à superfície. O crescimento dos poros vizinhos impede o crescimento em qualquer outra direção. ${ }^{16} \mathrm{O}$ crescimento vertical das paredes dos poros cria uma estrutura colunar que contém um canal circular, como mostram as Figuras 1, 12 e 13.
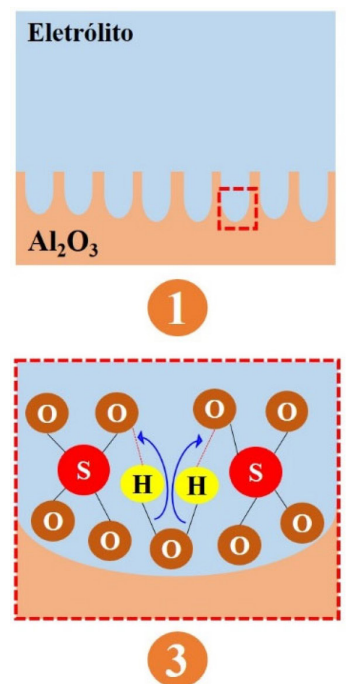

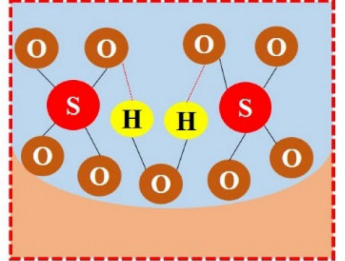

2.

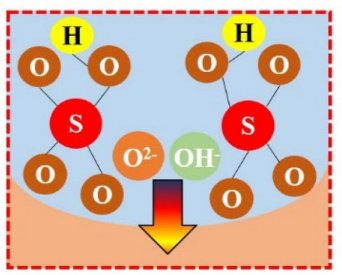

Os poros podem atingir diâmetros médios entre 10-150 nm. ${ }^{72}$ Enquanto a espessura dessa camada tende a variar de acordo com tipo de eletrólito, desde $0,5 \mu \mathrm{m}$ para camadas decorativas brilhantes, e até $150 \mu \mathrm{m}$ para aplicações arquitetônicas. O método de anodização mais amplamente utilizado, ou seja, o que é realizado em solução com $\mathrm{H}_{2} \mathrm{SO}_{4}$, produz uma camada de óxido cuja espessura varia entre 1,8 $\mu \mathrm{m}$ e $25 \mu \mathrm{m}$. Vale ressaltar que $67 \%$ da CA penetra no substrato e $33 \%$ cresce na superfície do mesmo. A anodização com $\mathrm{H}_{2} \mathrm{SO}_{4}$ é excelente para coloração da superfície devido à sua natureza permeável. ${ }^{72} \mathrm{O}$ revestimento formado por esse método age como excelente base para primers e tintas, ${ }^{188}$ como mostra a Figura 9.

Como mencionado, $\mathrm{o}_{2} \mathrm{SO}_{4}$ tem sido um dos eletrólitos mais utilizados durante o processo de anodização. O' Sullivan e Wood ${ }^{45}$ explicaram que os íons $\mathrm{O}^{2-} \mathrm{e} \mathrm{OH}^{-}$podem ser gerados pela interação das moléculas de $\mathrm{H}_{2} \mathrm{O}$ com os íons $\mathrm{SO}_{4}$, esses últimos sendo formado pela dissociação das moléculas de $\mathrm{H}_{2} \mathrm{SO}_{4}$, como mostra a reação (9).

$$
\mathrm{H}_{2} \mathrm{SO}_{4(\mathrm{aq})} \rightarrow \mathrm{H}_{(\mathrm{aq})}^{+}+\mathrm{HSO}_{4(\mathrm{aq})}^{-} \rightarrow 2 \mathrm{H}_{(\mathrm{aq})}^{+}+\mathrm{SO}_{4(\mathrm{aq})}^{2-}
$$

Os íons $\mathrm{SO}_{4}{ }^{2-}$ atuam como catalisador na formação da camada anodizada, pois ao interagirem com a água formada segundo reação (4), favorecem a formação dos íons $\mathrm{O}^{2-}$ e $\mathrm{OH}^{-}$. Dessa forma, o processo de anodização passa a ocorrer mais rapidamente e com maior eficiência. A Figura 14 exemplifica a interação entre os ânions $\mathrm{SO}_{4}{ }^{2-} \mathrm{e}$ as moléculas de $\mathrm{H}_{2} \mathrm{O}$. ${ }^{189}$

Figura 14. Representação esquemática da geração dos íons $\mathrm{O}^{2-}$ e $\mathrm{OH}$ a partir da interação das moléculas de água com os ânions $\mathrm{SO}_{4}^{2-}$ absorvidos. Baseado na ref. 189 
O estágio 1 ilustra o início da formação da CA. No estágio 2 ocorre a formação das pontes de hidrogênio entre os íons $\mathrm{SO}_{4}{ }^{2-} \mathrm{com}$ as moléculas de $\mathrm{H}_{2} \mathrm{O}$. Essa interação acontece entre os átomos de hidrogênio das moléculas de $\mathrm{H}_{2} \mathrm{O}$ e os átomos de oxigênios dos íons $\mathrm{SO}_{4}{ }^{2-}$. Posteriormente, esse processo tende a enfraquecer a ligação covalente entre $\mathrm{O}-\mathrm{H}$ presente na molécula de $\mathrm{H}_{2} \mathrm{O}$. Em consequência, o campo elétrico ajuda na quebra dessa ligação removendo o cátion $\mathrm{H}^{+}$de sua ligação original e o estabilizando em uma nova ligação covalente com os íons $\mathrm{SO}_{4}{ }^{2-}$, como exemplificado nos estágios 3 e 4 . Vale ressaltar que para a remoção de um cátion $\mathrm{H}^{+}$, os ânions $\mathrm{OH}^{-}$são formados, enquanto para dois cátions de $\mathrm{H}^{+}$ocorre a formação dos ânions $\mathrm{O}^{2-}$. Além disso, durante o processo de anodização, os ânions $\mathrm{SO}_{4}^{2-}$ podem penetrar na camada barreira substituindo os íons $\mathrm{O}^{2-}$, acelerando assim o processo. ${ }^{190}$

O estágio 5 exemplifica as principais etapas no desenvolvimento da camada anodizada, de acordo com as reações químicas (1) - (5) e (9), são elas:

1. Ejeção dos cátions para o eletrólito

2. Região de dissolução do óxido pela migração dos íons $\mathrm{SO}_{4}{ }^{2-}, \mathrm{O}^{2-} \mathrm{e}$ $\mathrm{OH}^{-}$

3. Óxido externo onde ocorre formação da camada porosa

4. Óxido interno onde ocorre a formação da camada barreira

5. Região de desenvolvimento do óxido primário (substrato)

Vale destacar, que durante o processo de anodização das ligas de $\mathrm{Al}$ é comumente observada a evolução de gases, ${ }^{124}$ tanto no ânodo (superfície da liga), pela geração de $\mathrm{O}_{2}$, como mostra a reação (6), quanto no cátodo, pela geração de $\mathrm{H}_{2}$, reação (7). $\mathrm{O}$ esquema da Figura 15 exemplifica esses fenômenos.
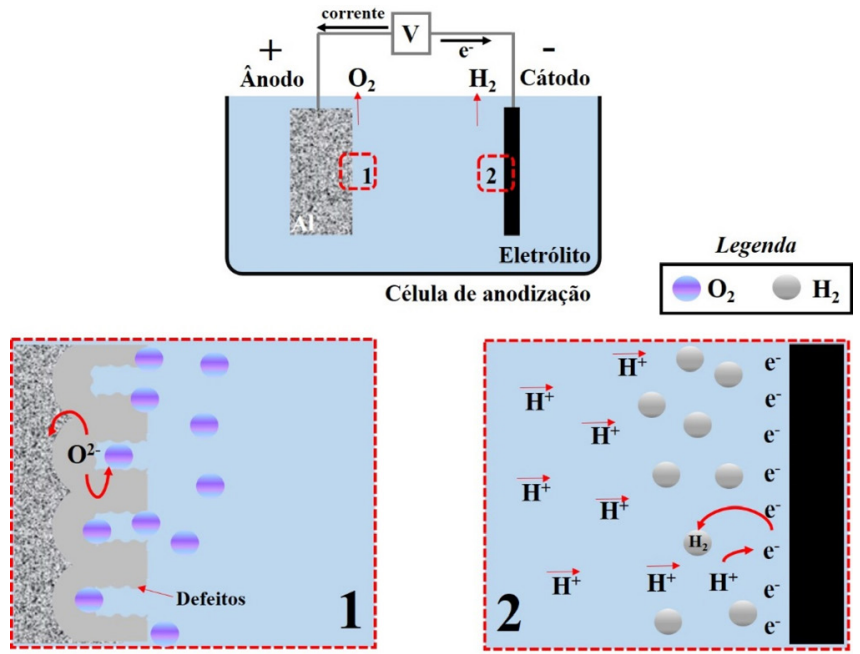

Figura 15. Ilustração esquemática da formação e liberação dos gases $\mathrm{O}_{2}$, no ânodo, e $\mathrm{H}_{2}$, no cátodo, durante o processo de anodização

A formação das bolhas de gás oxigênio acontece por um processo eletroquímico. Esse fenômeno pode ocorrer dentro da camada anódica, na interface metal/óxido, ou na superfície externa, óxido/ eletrólito. ${ }^{14}$ Os íons $\mathrm{O}^{2-}$ provenientes da eletrólise da água (reação 4), são oxidados pelos átomos de $\mathrm{Cu}$ e as impurezas presentes nas ligas de $\mathrm{Al}$ que atuam como áreas anódicas, formando assim nano bolhas de gás $\mathrm{O}_{2}$ dentro da $\mathrm{CA}$, as quais podem crescer e coalescer. $\mathrm{O}$ tamanho das bolhas varia de 10 a $100 \mathrm{~nm}$, podendo exercer pressão na camada e, como consequência, produzir filmes defeituosos, não uniformes. ${ }^{14,88,167}$ Vale destacar que, quanto maior for a quantidade de elementos de liga, maior será a formação de bolhas. ${ }^{14}$ Enquanto no cátodo ocorre a redução dos íons $\mathrm{H}^{+}$em excesso nas soluções ácidas, e eles, devido à sua alta mobilidade, ${ }^{121}$ tendem a reduzir na superfície do metal inerte no banho de anodização. Em resumo, a equação geral do processo de anodização é exemplificada na reação (8).

Após formação da camada anodizada, um dos processos mais utilizados na indústria como pós tratamento para o $\mathrm{Al}$ e suas ligas é a selagem. ${ }^{191}$ A selagem com água $\left(\mathrm{H}_{2} \mathrm{O}\right)$ é um dos métodos mais utilizados, sendo de baixo custo. ${ }^{191}$ A Figura 16 ilustra a CA não selada e selada.

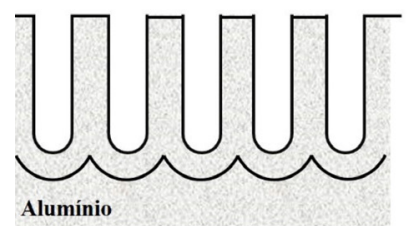

(a)

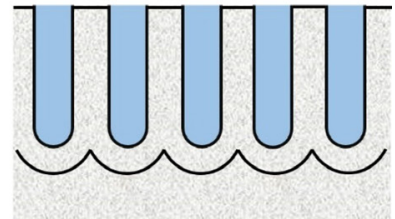

(b)
Figura 16. Ilustração esquemática da camada anodizada: (a) não selada e (b) selada com água

A vedação dos poros pela selagem em água produz pouca mudança no filme de óxido, mas causa o bloqueio, parcial ou total, dos poros, fechamento das regiões Inter cristalinas e formação de várias formas de alumina hidratada, sendo que a mais importante é provavelmente a boemita $(\mathrm{AlO}) \mathrm{OH}$, formada a partir da interação do oxido de alumínio com a água como mostra a reação abaixo. ${ }^{191}$

$$
\mathrm{Al}_{2} \mathrm{O}_{3(\mathrm{ox})}+\mathrm{H}_{2} \mathrm{O}_{(\mathrm{aq})} \rightarrow 2 \mathrm{AlO}(\mathrm{OH})_{(\mathrm{ox})}
$$

As principais propriedades produzidas pela selagem são: ${ }^{192}$ (a) aumento da resistência à corrosão; (b) redução da retenção de corantes; (c) aumento da impedância do filme anódico; (d) redução da dureza e resistência à abrasão; (e) redução da temperatura de fissuração térmica; (f) redução da adesão de revestimentos orgânicos, como tintas, lacas ou esmaltes.

A selagem normalmente é feita por imersão em água aquecida a $100{ }^{\circ} \mathrm{C}$, com um $\mathrm{pH}$ de $6,0 \pm 0,5$, por um período de $2-3$ minutos. Alguns sais de metal são frequentemente usados como aditivos de vedação. Os sais são absorvidos pela camada, na qual são hidrolisados e precipitados como hidróxidos. Vale destacar que, assim como no processo de anodização, a selagem crômica também vem sendo substituída nas linhas de produção devido às propriedades cancerígenas de seus rejeitos. ${ }^{193}$ Por sua vez, a selagem com cério tem se mostrado uma rota alternativa a esse processo, pois além de ser ambientalmente amigável, vem mostrando bons resultados. ${ }^{81}$

\section{CONSIDERAÇÕES FINAIS E FUTURAS PERSPECTIVAS}

Neste artigo é apresentada uma revisão histórica e eletroquímica sobre o processo de anodização do $\mathrm{Al}$ e suas ligas. A anodização é um processo eletroquímico que produz óxidos estáveis na superfície dos metais. O revestimento anódico pode ser produzido no Al e suas ligas usando uma ampla variedade de eletrólitos. Comparado com outros processos de proteção contra corrosão, a anodização do Al é um processo de baixo custo. Esse processo tem sido objeto de estudo há várias décadas, porém, um grande aumento de publicações ocorreu a partir dos anos 90, devido ao advento da nanotecnologia. As variações dos parâmetros experimentais desse processo permitem um amplo campo de aplicação. Dessa forma, o processo de anodização do Al tornou-se cada vez mais versátil, abrindo uma ampla variedade de futuras aplicações. Acredita-se que desenvolvimentos inovadores nesse campo de pesquisa serão motivados pelo desejo de gerar novas e incomuns arquiteturas de nanoporos com propriedades avançadas, abrindo caminhos para futuras aplicações em áreas de 
interesse tecnológico e da engenharia estrutural, como nos estudos da anodização auto-organizada e pré-texturizada.

\section{AGRADECIMENTOS}

Os autores agradecem à FAPESP (Processos 2019/18388-1 e 2018/06880-6) e ao CNPq (Processo 426280/2016-4) pelo apoio financeiro a esta pesquisa.

\section{REFERENCIAS}

1. Lumley, R. N.; Fundamentals of Aluminium Metallurgy, $1^{\text {st }}$ ed., Elsevier: United Kingdom, 2018.

2. Berthier, P.; Annales des mines ou Recueil de memoires sur l'exploitation des mines et sur les sciences qui s'y rapportent, $1^{\text {st }}$ ed., Annales des Mines: France, 1821.

3. James, F. K.; The Aluminium Industry, $1^{\text {st }}$ ed., Elsevier: United Kingdom, 2001.

4. Ruys, A.; Alumina Ceramics, ${ }^{\text {st }}$ ed., Elsevier: United Kingdom, 2019.

5. Mazzolani, F.; Aluminium Alloy Structures, $2^{\text {nd }}$ ed., Taylor and Francis: Oxfordshire, 2014

6. Totten, G. E.; MacKenzie, D. S.; Handbook of Aluminum, $2^{\text {nd }}$ ed., Taylor and Francis: Oxfordshire, 2003.

7. Munday, P.; Environmental History 2014, 20, 319.

8. Vargel, C.; Jacques, M.; Schmidt, M. P.; Corrosion of Aluminium, $1^{\text {st }}$ ed., Elsevier: Oxford, 2004.

9. Araujo, J.; Silva, R.; Milagre, M.; Machado, C.; Costa, I.; Quim. Nova, 2020, 43, 1058.

10. Pedeferri, P.; Engineering Materials Corrosion Science and Engineering, $1^{\text {st }}$ ed., Springer: New York, 2018.

11. Runge, J. M.; The Metallurgy of Anodizing Aluminum, $1^{\text {st }}$ ed., Springer: New York, 2018.

12. Kawai, S.; Anodizing and Coloring of Aluminum Alloys, $1^{\text {st }}$ ed., Finishing Publications: Michigan, 2002.

13. Cramer, S. D.; Covino Jr., B. S.; ASM Handbook Volume 13B: Corrosion: Materials, ASM International: United States of America, 2005.

14. Thompson, G. E.; Habazaki, H.; Shimizu, K.; Sakairi, M.; Skeldon, P.; Zhou, X.; Wood, G. C.; Aircraft Engineering and Aerospace Technology 1999, 71, 228.

15. Lee, W.; Corrosion 2010, 62, 57.

16. Md Jani, A. M.; Losic, D.; Voelcker, N. H.; Prog. Mater. Sci. 2013, 58, 636.

17. Wheatstone, C.; Proc. R. Soc. London. 1855, 7, 369.

18. Buff, H.; Ann. Chem. Pharm. 1857, 102, 265.

19. Ducretet, M. E.; J. Phys. Theor. Appl. 1875, 4, 84.

20. Pollak, C.; German Patent: Elektrischer Flüssigkeitskondensator Mit Aluminiumelektroden, CA 92564, 1897.

21. Bengough, G. D.; Sutart, J. M.; British Patent: Improved Process of Protecting Surfaces of Aluminium or Aluminium Alloys, GB223994A, 1923.

22. Flick, F. B.; US Pat. US1526127A 1925.

23. Pacz, A.; US Pat. US1551613A 1925.

24. Gower, C. H. R.; British Patent: An Improved Process for Providing a Resistant Coating upon the Surfaces of Aluminium and Aluminium Alloys, GB223994A, 1928.

25. Kanematsu, H.; Barry, D. M.;. Corrosion Control and Surface Finishing, $1^{\text {st }}$ ed., Springer: New York, 2016.

26. Setoh, S.; Miyata, A.; Sci. Pap. 1932, 19, 237.

27. Burgers, W. G.; Claassen, A.; Zernike, J.; Z. Phys. 1932, 74, 593.

28. Besser, B. P.; Radio Sci. 2007, 42, 1.

29. Rummel, T.; Mitteilung Aus Dem Elektrophysikalischen Lab. Des Elektrotechnishcen Institiutes, Tech. Hochschule, München. 1936, 2, 518.
30. Baumaun, W.; Z. Phys. 1939, 111, 708

31. Güntherschulze, A.; Betz, H.; Z. Phys. 1934, 92, 367.

32. Verwey, E. J. W.; Physica 1935, 2, 1059.

33. Edwards, J. D.; Keller, F.; Electrochem. Soc. 1940, 79, 133.

34. Mott, N. F.; Trans. Faraday Soc. 1947, 43, 429

35. Cabrera, N.; Mott, N. F.; Reports Prog. Phys. 1949, 12, 308.

36. Wernick, S.; Nature 1948, 162, 834.

37. Keller, F.; Hunter, M. S.; Robinson, D. L.; J. Electrochem. Soc. 1953, $100,411$.

38. Wernick, S.; Pinner, R.; Sheasby, P. G.; The Surface Treatment and Finishing of Aluminum and Its Alloys, $6^{\text {th }}$ ed., ASM International: Middlesex, 2001.

39. Hoar, T. P.; Mott, N. F.; J. Phys. Chem. Solids 1959, 9, 97.

40. Davies, J. A.; Pringle, J. P. S.; Graham, R. L.; Brown, F.; J. Electrochem. Soc. 1962, 109, 999.

41. Davies, J. A.; Domeij. B.; Pringle, J. P. S.; Brown, F.; J. Electrochem. Soc. 1965, 112, 675.

42. Diggle, J. W.; Downie, T. C.; Goulding, C. W.; Chem. Rev. 1969, 69, 365.

43. Arthur W. B.; Technology of Anodizing Aluminium, $3^{\text {rd }}$ ed., Modena: Italy, 1969.

44. Williams, D. B.; Carter, C. B.; Transmission Electron Microscopy, $1^{\text {st }}$ ed., Springer: New York, 2009.

45. O’Sullivan, J. P.; Wood, G. C.; Proc. R. Soc. London. A. Math. Phys. Sci. 1970, 317, 511.

46. O'Sullivan, J. P.; Hockey, J. A.; Wood, G. C.; Trans. Faraday Soc. 1971, $67,535$.

47. Thompson, G. E.; Furneaux, R. C.; Goode, J. S.; Wood, G. C.; Trans. IMF 1978, 56, 159 .

48. Thompson, G. E.; Wood. G. C.; Nature 1981, 290, 230.

49. Thompson, G. E.; Xu, Y.; Skeldon, P.; Shimizu, K.; Han, S. H.; Wood, G. C.; Philos. Mag. B 1987, 55, 651.

50. Skeldon, P.; Shimizu, K.; Thompson, G. E.; Wood, G. C.; Surf. Interface Anal. 1983, 5, 247.

51. Dell'oca, C. J.; Pulfrey, D. L.; Young. L.; Phys. Thin Films. 1971, 6, 1.

52. Henley V. F.; Anodic Oxidation of Aluminium and its Alloys, $1^{\text {st }} \mathrm{ed}$., Pergamont Oxford: United Kingdon, 1982.

53. Harscoet, E.; Froelich, D.; J. Clean. Prod. 2008, 16, 1294.

54. Eichinger, E.; Osborne, J.; Van Cleave, T.; Met. Finsh. 1997, 95, 36.

55. Zhou, F.; Tese de Doutorado, Manchester University, United Kingdom, 2011.

56. Parkhutik, V. P.; Shershulsky, V. I.; J. Phys. D: Appl. Phys. 1992, 25, 1258.

57. Liu, Y.; Skeldon, P.; Thompson, G. E.; Habazaki, H.; Shimizu, K.; Corros. Sci. 2002, 44, 1133.

58. Iglesias-Rubianes, L.; Garcia-Vergara, S. J.; Skeldon, P.; Thompson, G. E.; Ferguson, J.; Beneke, M.; Electrochim. Acta 2007, 52, 7148.

59. Prada Ramirez, O. M.; Queiroz, F. M.; Terada, M.; Donatus, U.; Costa, I.; Olivier, M. G.; Melo, H. G.; Surf. Interface Anal. 2019, 1.

60. Machado, C.; Klumpp, R. E.; Ayusso, V. H.; Donatus, U.; Milagre, M. X.; Araujo, J. V.; Glauson, G. A.; Costa, I.; Surf. Interface Anal. 2019, 1.

61. Prada Ramirez, O. M.; Queiroz, F. M.; Tunes, M. A.; Antunes, R. A.; Rodrigues, C. L.; Lanzutti, A.; Pogatscher, S.; Olivier, M. G.; Melo, H. G.; Appl. Surf. Sci. 2020, 534, 147634.

62. Lee, W.; Park, S. J.; Chem. Rev. 2014, 114, 7487.

63. https://doi.org/10.1021/cr500002z, acessada em Março 2021.

64. Oelund, J. C.; Fullen, W. J.; Crump, D. L.; US pat. O06149795A 1999.

65. Stancin, L. C.; Douglas, L.; US pat. US006149795A 2002.

66. Dattilo, C.; Tamiro, A.; Romano, S.; US pat. 0002825 A1 2002.

67. Esteban, P. O.; Rubio, M. G.; Diego, I. G.; Gonzalez-Escalada, M. A. L.; US pat. 0107848 2008.

68. Balaraju, J. N.; Yoganandan, G.; US pat. 0002825 Al 2016. 
69. Dick, L. F. P.; Takimi, A. S.; Melo, Y. R.; Dick, P. A.; Br PI 102016027731-0 A2, 2016.

70. L. F. P. Dick, A. S. Takimi, Y. R. Melo, and P. A. Dick, Br PI 102017008478-7 A2, 2017.

71. Blatt, R. G.; Met. Finsh. 1999, 97, 120

72. Mathew, N.; Journal for Research 2016, 2, 5 .

73. https:// www.webofknowledge.com, acessada em Março 2021.

74. https:// https://www.scopus.com/home.uri, acessada em Março 2021.

75. Palomino, L. E. M.; Tese de Doutorado, Universidade de São Paulo, 2007.

76. Yanlong, M.; Tese de Doutorado, Manchester University, United Kingdom, 2011.

77. Huamanrayme, R. B.; Tese de Doutorado, Universidade de São Paulo, 2012.

78. Dawod, E.; Tese de Doutorado, Manchester University, United Kingdom, 2016.

79. Baiwei, Z.; Tese de Doutorado, Jönköping University, Sweden, 2017.

80. Alvarez, J. M. T.; Tese de Doutorado, Manchester University, United Kingdom, 2018.

81. Ramirez, O. M. P.; Tese de Doutorado, Universidade de São Paulo, Brasil, 2019.

82. Guadagnin, H. C.; Tese de Doutorado, Universidade de São Paulo, Brasil, 2017.

83. Rodrigues, M. P. S.; Tese de Doutorado, Universidade Estadual de Ponta Grossa, Brasil, 2012.

84. https:// www.scival.com, acessado em Março 2021.

85. Garcia-Vergara, S. J.; El Khazmi, K.; Skeldon, P.; Thompson, G. E.; Corros. Sci. 2006, 48, 2937.

86. Zhou, X.; Thompson, G. E.; Skeldon, P.; Electrochim. Acta 2008, 53, 5684.

87. Garcia-Vergara, S. J.; Skeldon, P.; Thompson, G. E.; Habazaki, H.; Electrochim. Acta 2006, 52, 681.

88. Zhou, X.; Thompson, G. E.; Skeldon, P.; Wood, G. C.; Shimizu, K.; Habazaki, H.; Corros. Sci. 1999, 41, 1599.

89. Garcia-Vergara, S. J.; Skeldon, P.; Thompson, G. E.; Habazaki, H.; Surf. Interface Anal. 2007, 39, 860.

90. Zhuravlyova, E.; Iglesias-Rubianes, L.; Pakes, A.; Skeldon, P.; Thompson, G. E.; Zhou, X.; Quance, T.; Graham, M. J.; Habazaki, H.; Shimizu, K.; Corros. Sci. 2002, 44, 2153.

91. Thompson, G. E.; Thin Solid Films. 1997, 297, 192.

92. Skeldon, P.; Shimizu, K.; Thompson, G. E.; Wood, G. C.; Philos. Mag. B 1995, 72, 391.

93. Thompson, G. E.; Furneaux, R. C.; Wood, G. C.; Trans. Inst. Met. Finish. 1997, 55, 117.

94. Zhou, X.; Thompson, G. E.; Habazaki, H.; Shimizu, K.; Skeldon, P.; Wood, G. C.; Thin Solid Films 1997, 293, 327.

95. Ma, Y.; Zhou, X.; Wang, J.; Thompson, G. E.; Huang, W.; Nilsson, J. O.; Gustavsson, M.; Crispin, A.; J. Electrochem. Soc. 2014, 161, C312.

96. Thompson, G. E.; Zhang, L.; Smith, C. J. E.; Skeldon, P.; Corrosion 1999, 55, 1052.

97. Xu, Y.; Thompson, G. E.; Wood, G. C.; Trans. IMF 1985, 63, 98.

98. Habazaki, H.; Shimizu, K.; Skeldon, P.; Thompson, G. E.; Wood, G. C.; Zhou, X.; Trans. Inst. Met. Finish. 1997, 75, 8.

99. Crossland, A. C.; Habazaki, H.; Shimizu, K.; Skeldon, P.; Thompson, G. E.; Wood, G. C.; Zhou, X.; Smith, C. J. E.; Corros. Sci. 1999, 41, 1945.

100. Thompson, G. E.; Furneaux, R. C.; Wood, G. C.; Richardson, J. A.; Goode, J. S.; Nature 1978, 272, 433.

101. Ma, Y.; Wu, H.; Zhou, X.; Li, K.; Liao, Y.; Liang, Z.; Liu, L.; Corros. Sci. 2019, 158, 108110.

102. Ma, Y.; Zhou, X.; Thompson, G. E.; Zhang, X.; Luo, C.; Curioni, M.; Liu, H.; J. Electrochem. Soc. 2013, 160, C111.

103. Ma, Y.; Ma, Y.; Li, K.; Zhou, X.; Wu, H.; Zhu, P.; Yang, B.; Liao, Y.; He, S.; Electrochem. Soc. 2020, 167, C369.
104. Ma, Y.; Zhou, X.; Thompson, G. E.; Nilsson, J. O.; Gustavsson, M.; Crispin, A.; Trans. Inst. Met. Finish. 2013, 91, 11.

105. Ma, Y.; Zhou, X.; Li, K.; Pawar, S.; Liao, Y.; Jin, Z.; Wang, Z.; Wu, H.; Liang, Z.; Liu, L.; J. Electrochem. Soc. 2019, 166, C296.

106. Wu, H.; Ma, Y.; Huang, W.; Zhou, X.; Li, K.; Liao, Y.; Wang, Z.; Liang, Z.; Liu, L.; J. Electrochem. Soc. 2018, 165, C573.

107. Ma, Y.; Zhou, X.; Liao, Y.; Chen, X.; Zhang, C.; Wu, H.; Wang, Z.; Huang, W.; J. Electrochem. Soc. 2016, 163, C369.

108. Ma, Y.; Zhou, X.; Thompson, G. E.; Curioni, M.; Skeldon, P.; Zhang, X.; Sun, Z.; Luo, C.; Tang, Z.; Lu, F.; Electrochim. Acta 2012, 80, 148.

109. Ma, Y.; Zhou, X.; Thompson, G. E.; Curioni, M.; Zhong, X.; Koroleva, E.; Skeldon, P.; Thomson, P.; Fowles, M.; Corros. Sci. 2011, 53, 4141.

110. Ma, Y.; Zhou, X.; Thompson, G. E.; Curioni, M.; Hashimoto, T.; Skeldon, P.; Koroleva, E.; Electrochem. Solid-State Lett. 2012, 15, E4.

111. Ma, Y.; Zhou, X.; Thompson, G. E.; Curioni, M.; Hashimoto, T.; Skeldon, P.; Thomson, P.; Fowles, M.; J. Electrochem. Soc. 2011, 158, C17.

112. Curioni, M.; Skeldon, P.; Thompson, G. E.; Ferguson, J.; Adv. Mater. Res. 2008, 38, 48.

113. Saenz M. M.; Curioni, M.; Skeldon, P.; Thompson, G. E.; Surf. Interface Anal. 2010, 42, 241.

114. Usman, B. J.; Scenini, F.; Curioni, M.; Prog. Org. Coatings 2020, 144, 105648.

115. Curioni, M.; Skeldon, P.; Ferguson, J.; Thompson, G. E.; J. Appl. Electrochem. 2011, 41, 773.

116. Zhang, L.; Thompson, G. E.; Curioni, M.; Skeldon, P.; J. Electrochem. Soc. 2013, 160, C179.

117. Torrescano-Alvarez, J. M.; Curioni, M.; Zhou, X.; Skeldon, P.; Surf. Interface Anal. 2019, 51, 1135.

118. Curioni, M.; Gionfini, T.; Vicenzo, A.; Skeldon, P.; Thompson, G. E.; Surf. Interface Anal. 2013, 45, 1485.

119. Usman, B. J.; Scenini, F.; Curioni, M.; J. Electrochem. Soc. 2020, 167, 041505.

120. Curioni, M.; Roeth, F.; Garcia-Vergara, S. J.; Hashimoto, T.; Skeldon, P.; Thompson, G. E.; Ferguson, J.; Surf. Interface Anal. 2010, 42, 234.

121. Curioni, M.; Scenini, F.; Electrochim. Acta 2015, 180, 712.

122. Curioni, M.; Saenz, M. M.; Skeldon, P.; Thompson, G. E.; Ferguson, J.; J. Electrochem. Soc. 2008, 155, C387.

123. Curioni, M.; Skeldon, P.; Thompson, G. E.; J. Electrochem. Soc. 2009, 156, C407.

124. Torrescano-Alvarez, J. M.; Curioni, M.; Skeldon, P.; J. Electrochem. Soc. 2017, 164, C728.

125. Habazaki, H.; Shimizu, K.; Skeldon, P.; Thompson, G. E.; Wood, G. C.; Zhou, X.; J. Phys. D: Appl. Phys. 1997, 30, 1833.

126. García-Rubio, M.; Ocón, P.; Climent-Font, A.; Smith, R. W.; Curioni, M.; Thompson, G. E.; Skeldon, P.; Lavía, A.; García, I.; Corros. Sci. 2009, 51, 2034.

127. Saenz M. M.; Curioni, M.; Skeldon, P.; Thompson, G. E.; Corros. Sci. 2010, 52, 2489

128. García-Rubio, M.; Ocón, P.; Curioni, M.; Thompson, G. E.; Skeldon, P.; Lavía, A.; García, I.; Corros. Sci. 2010, 52, 2219.

129. Elaish, R.; Curioni, M.; Gowers, K.; Kasuga, A.; Habazaki, H.; Hashimoto, T.; Skeldon, P.; J. Electrochem. Soc. 2017, 164, C831.

130. Saenz de Miera, M.; Curioni, M.; Skeldon, P.; Thompson, G. E.; Corros. Sci. 2008, 50, 3410.

131. Curioni, M.; Skeldon, P.; Koroleva, E.; Thompson, G. E.; Ferguson, J.; J. Electrochem. Soc. 2009, 156, C147.

132. Shimizu, K.; Thompson, G. E.; Wood, G. C.; Xu, Y.; Thin Solid Films 1982, 88, 255.

133. Shimizu, K.; Thompson, G. E.; Wood, G. C.; Kurima, Y.; Kobayashi, K.; Thin Solid Films 1989, 173, 263.

134. Habazaki, H.; Shimizu, K.; Skeldon, P.; Thompson, G. E.; Wood, C. G.; Zhou, X.; Corros. Sci. 1997, 39, 731. 
135. Habazaki, H.; Shimizu, K.; Paez, M. A.; Skeldon, P.; Thompson, G. E.; Wood, G. C.; Xhou, X.; Surf. Interface Anal. 1995, 23, 892.

136. Skeldon, P.; Thompson, G. E.; Wood, G. C.; Zhou, X.; Habazaki, H.; Shimizu, K.; Philos. Mag. A 1997, 76, 729.

137. Alexander, M. R.; Thompson, G. E.; Zhou, X.; Beamson, G.; Fairley, N.; Surf. Interface Anal. 2002, 34, 485.

138. Rodrik, D.; Novos Estudos CEBRAP 2011, 89, 59.

139. Nonnenberg, M. J. B.; Rev. Econ. Polit. 2010, 30, 201.

140. Li, R.; Leung, G. C. K.; Energy Policy 2011, 39, 5159.

141. Terada, M.; Queiroz, F. M.; Aguiar, D. B. S.; Ayusso, V. H.; Costenaro, H.; Olivier, M. G.; Melo, H. G.; Costa, I.; Surf. Coatings Technol. 2019, $372,422$.

142. Queiroz, F. M.; Bugarin, A. F. S.; Hammel, N. P.; Capelossi, V. R.; Terada, M.; Costa, I.; Surf. Interface Anal. 2016, 48, 755.

143. Donatus, U.; Ferreira, R. O; Mogili, N. V. V; de Viveiros, B. V. G.; Milagre, M. X; Costa, I.; Mater. Chem. Phys. 2018, 219, 493.

144. de Souza, K. P.; Tese de Doutorado, Universidade de São Paulo, Brasil, 2006.

145. Terada, M.; Queiroz, F. M.; Costenaro, H.; Ayusso, V. H.; Olivier, M.; Costa, I.; Melo, H. G.; Corrosion 2019, 75, 110.

146. Costenaro, H.; Queiroz, F. M.; Terada, M.; Olivier, M. G; Costa, I.; Melo, H. G.; Key Eng. Mater. 2016, 710, 210.

147. Costenaro, H.; Lanzutti, A.; Paint, Y.; Fedrizzi, L.; Terada, M.; Melo, H. G.; Olivier, M. G.; Surf. Coatings Technol. 2017, 324, 438.

148. Atz Dick, P.; Knörnschild, G,H.; Dick, L. F. P.; Corros. Sci. 2017, 114, 28.

149. Machado, T. V.; Dick, P. A.; Knörnschild, G. H.; Dick, L. F. P.; Surf. Coatings Technol. 2020, 383, 125283.

150. Atz, N. R.; Tese de Doutorado, Universidade Federal do Rio Grande do Sul, Brasil, 2005.

151. Villanova, R. L.; Tese de Doutorado, Universidade Federal do Rio Grande do Sul, Brasil, 2007.

152. Dick, P. A.; Tese de Doutorado, Universidade Federal do Rio Grande do Sul, Brasil, 2019.

153. Feil, A. F.; Tese de Doutorado, Universidade Federal do Rio Grande do Sul, Brasil, 2011.

154. Feil, A. F.; Costa, M. V.; Amaral, L.; Teixeira, S. R.; Migowski, P.; J. Appl. Phys. 2010, 107, 5.

155. Pinheiro, J. S.; Tese de Doutorado, Universidade Federal do Rio Grande do Sul, Brasil, 2019.

156. Minto, T. A.; Dissertação de Mestrado, Universidade Estadual Paulista, Brasil, 2012.

157. Castro, V. A.; Dissertação de Mestrado, Universidade Estadual Paulista, Brasil, 2018

158. Alves, G.; Tese de Doutorado, Universidade Estadual de Ponta Grossa, Brasil, 2012

159. Alves, G. J. T.; Maia, G. A. R.; Antunes, S. R. M.; Oliveira, M. F.; Cunha, M. T.; Rodrigues, P. R. P.; Mater. Res. Express 2019, 6, 016509.

160. https://abts.org.br/, acessada em Junho 2020.

161. Poinern, G. E. J.; Ali, N.; Fawcett, D.; Materials 2011, 4, 487.

162. Beri, R.; Kushwaha, M. K.; Grover, N.; International Research Journal of Engineering and Technology 2017, 4, 778.
163. http://www.eaa.net/eaa/education/TALAT, acessada em Março 2021

164. Zhu, P.; Ma, Y.; Li, K.; Liang, Z.; Yang, B.; Huang, W.; Liao, Y.; Surf. Coatings Technol. 2020, 394, 125852.

165. Twite, R. L.; Bierwagen, G. P.; Prog. Org. Coatings 1998, 33, 91.

166. Donahue, C. J.; Exline, J. A.; J. Chem. Educ. 2014, 91, 711.

167. Skeldon, P.; Zhou, X.; Thompson, G. E.; Wood, G. C.; Habazaki, H.; Shimizu, K.; Corrosion 1999, 55, 561.

168. Kulinich, S. A.; Akhtar, A. S.; Wong, P. C.; Wong, K. C.; Mitchell, K. A. R.; Thin Solid Films 2017, 515, 8386.

169. Grubbs, C. A.; Met. Finish. 2007, 105, 397.

170. Tajima, S.; Advances in Corrosion Science and Technology Advances in Corrosion Science and Technology, $1^{\text {st }}$ ed., Plenum Press: New York, 1970 .

171. Wielage, B.; Alisch, G.; Lampke, T.; Nickel, D.; Key Eng. Mater. 2008, 384, 263.

172. Ozawa, K.; Majima, T.; J. Appl. Phys. 1996, 80, 5828.

173. Moutarlier, V.; Gigandet, M. P.; Pagetti, J.; Ricq, L.; Surf. Coatings Technol. 2003, 173, 87 .

174. Saeedikhani, M.; Javidi, M.; Yazdani, A.; Trans. Nonferrous Met. Soc. China 2013, 23, 2551.

175. Lee, J.; Kim, Y.; Jung, U.; Chung, W.; Mater. Chem. Phys. 2013, 141, 680 .

176. Zaraska, L.; Jaskuła, M.; Sulka, G. D.; Mater. Lett. 2016, 171, 315.

177. Survila, E.; Trans. Inst. Met. Finish. 1984, 62, 45.

178. Furneaux, R. C.; Rigby, W. R.; Davidson, A. P.; Nature 1989, 337, 147.

179. Zhu, X. F.; Song, Y.; Liu, L.; Wang, C. Y.; Zheng, J.; Jia, H. B.; Wang, X. L.; Nanotechnology 2009, 20, 475303.

180. Palibroda, E.; Lupsan, A.; Pruneanu, S.; Savos, M.; Thin Solid Films 1995, 256, 101

181. Tao, X.; Shangkui, Q.; Jiazheng, Z.; Jianmin, C.; J. Phys. D: Appl. Phys. 1996, 29, 2534.

182. Lohrengel, M. M.; Mater. Sci. Eng. R Reports. 1993, 11, 243.

183. Runge, J. M.; Pomis, A. J.; Aesf Sur/Fin 2000, 8, 266.

184. Su, Z.; Bühl, M.; Zhou, W.; J. Am. Chem. Soc. 2009, 131, 8697.

185. Runge, J. M.; Apresentado no XII Encontro Brasileiro de Tratamento de Superfícies Brats e II Encontro Interfinanceiro Latino-Americano de São Paulo, 10 de maio de 2006.

186. Skeldon, P.; Thompson, G. E.; Garcia-Vergara, S. J.; Iglesias-Rubianes, L.; Blanco-Pinzon, C. E.; Electrochem. Solid-State Lett. 2006, 9, B47.

187. Garcia-Vergara, S.; Iglesias-Rubianes, L.; Blanco-Pinzon, C.; Skeldon, P.; Thompson, G.; Campestrini, P.; Proc. R. Soc. A 2006, 462, 2345.

188. Arrowsmith, D. J.; Clifford, A. W.; Int. J. Adhes. Adhes. 1983, 3, 193.

189. Sarraf, M.; Nasiri-Tabrizi, B.; Dabbagh, A.; Basirun, W. J.; Sukiman, N. L.; Ceram. Int. 2020, 46, 7306.

190. Nielsch, K.; Choi, J.; Schwirn, K.; Wehrspohn, R. B.; Gösele, U.; Nano Lett. 2002, 2, 677 .

191. Hao, L.; Cheng, B. R.; Met. Finish. 2000, 98, 8.

192. Ahmadun, M. B. H.; Dawson, J. L.; Thompson, G. E.; Trans. Inst. Met. Finish. 1990, 68, 109.

193. OSHA, Toxic and Hazardous Substances in Occupational Exposure to Hexavalent Chromium, 2006, United States Department of Labor; European REACH (EC n ${ }^{\circ}$ 907/2006). 